\title{
Circadian Redox and Metabolic Oscillations in Mammalian Systems
}

\author{
John S. O'Neill and Kevin A. Feeney
}

\begin{abstract}
Significance: A substantial proportion of mammalian physiology is organized around the day/night cycle, being regulated by the co-ordinated action of numerous cell-autonomous circadian oscillators throughout the body. Disruption of internal timekeeping, by genetic or environmental perturbation, leads to metabolic dysregulation, whereas changes in metabolism affect timekeeping. Recent Advances: While gene expression cycles are essential for the temporal coordination of normal physiology, it has become clear that rhythms in metabolism and redox balance are cell-intrinsic phenomena, which may regulate gene expression cycles reciprocally, but persist in their absence. For example, a circadian rhythm in peroxiredoxin oxidation was recently observed in isolated human erythrocytes, fibroblast cell lines in vitro, and mouse liver in vivo. Critical Issues: Mammalian timekeeping is a cellular phenomenon. While we understand many of the cellular systems that contribute to this biological oscillation's fidelity and robustness, a comprehensive mechanistic understanding remains elusive. Moreover, the formerly clear distinction between "core clock components" and rhythmic cellular outputs is blurred since several outputs, for example, redox balance, can feed back to regulate timekeeping. As with any cyclical system, establishing causality becomes problematic. Future Directions: A detailed molecular understanding of the temporal crosstalk between cellular systems, and the coincidence detection mechanisms that allow a cell to discriminate clock-relevant from irrelevant stimuli, will be essential as we move toward an integrated model of how this daily biological oscillation works. Such knowledge will highlight new avenues by which the functional consequences of circadian timekeeping can be explored in the context of human health and disease. Antioxid. Redox Signal. 20, 2966-2981.
\end{abstract}

\section{Introduction}

C IRCADIAN RHYTHMS ARE biological oscillations that persist in the absence of external cues, with a period of $\sim 1$ day. The phase of these "living clocks" is entrained by relevant environmental cues such as light or feeding, and unlike most biological processes the period of the oscillation is temperature compensated $\left(Q_{10} \sim 1\right)$ that is, the clock does not run faster on hot days (29). The ability to anticipate, and resonate with the day/night cycle is presumed to have conferred a constant selective pressure over the last billion or so years such that the vast majority of eukaryotes and many prokaryotes possess intrinsic circadian timekeeping (114). In mammals, circadian rhythms are manifest in the temporal organization of behavioral, physiological, cellular, and sub- cellular processes (see Fig. 1) -influencing phenomena as varied as sleep/wake cycles, glucose homeostasis, innate immunity, and cell division $(9,40,137)$. Recent investigations have found that an estimated third of genes in the mouse genome undergo daily oscillations in one or more tissues (J. Hogenesch, verbal communication). Because these endogenous oscillations interact with myriad biological systems, circadian disruption has significant impacts upon human health and the diseased state. For example, the chronic circadian dysregulation experienced by long-term shift workers ( $\sim 15 \%$ of the workforce in developed nations) is associated with an increased susceptibility to cardiovascular disease, type II diabetes, and various forms of cancer (109).

Metabolism is the complete set of enzyme-catalyzed reactions that allow organisms to grow and reproduce, maintain

MRC Laboratory of Molecular Biology, Cambridge, United Kingdom. 
FIG. 1. A hierarchy of rhythms in mammalian systems. Circadian rhythms are observed at every level of biological scale with causation acting in both directions. Appropriate environmental cues can evoke changes of rhythmic gene expression and cellular processes, whereas changes in gene expression and cellular activity ultimately regulate behavioral phenotypes such as the sleep/wake cycle. Unlike most mammals, humans have direct control over many environmental factors, for example, electrical lighting, adding an additional layer of complexity. Diagram inspired by Noble (97).

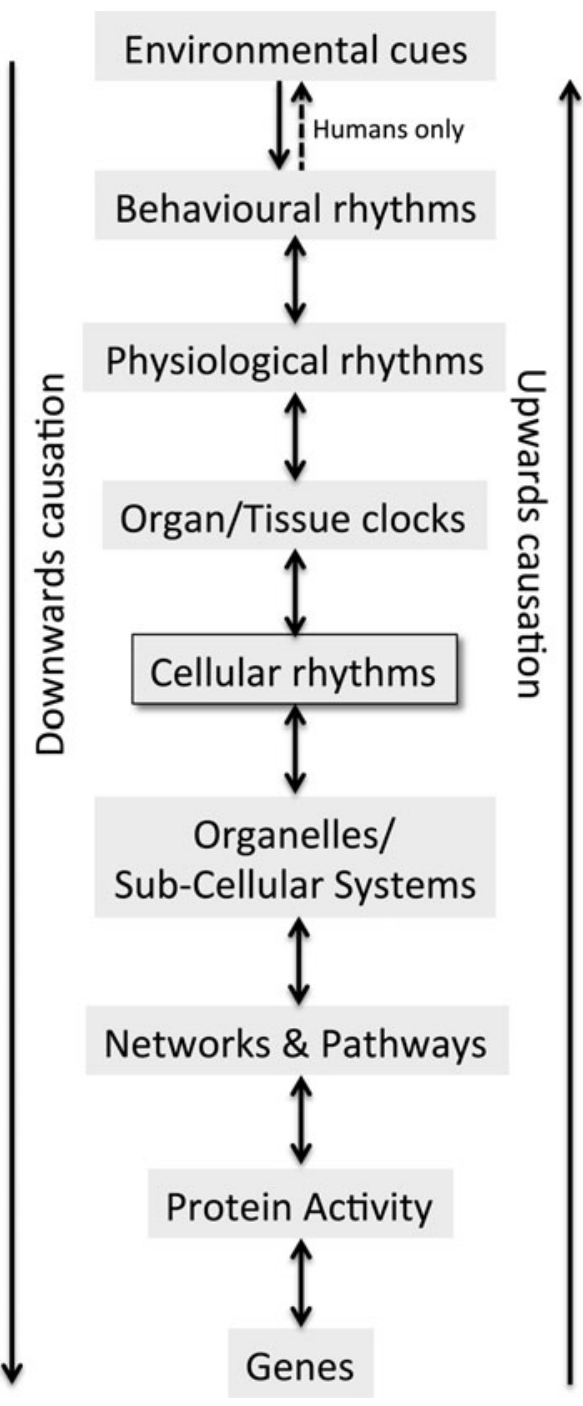

e.g. Light, food supply, Temperature, social cues

e.g. Feeding, sleep/wake, activity, social interaction

e.g. Body temperature, glucose homeostasis

e.g. Paracrine, endocrine signalling, transport processes

e.g. Proliferation, motility, secretion/ uptake, carbohydrate \& lipid metabolism

e.g. Mitochondrial activity, redox balance, autophagy, membrane potential, cytoskeleton, vesicle trafficking

e.g. Metabolic flux, signal transduction, ROS production, redox balance

e.g. 'Clock proteins', glycogen synthase kinase 3 , sirtuins, proteasomal degradation

e.g. 'Clock genes' and myriad tissue-specific targets their structures, and respond to their environments. Metabolism may be subdivided into energy-consuming biosynthetic or anabolic processes, and energy-liberating degradative or catabolic processes. In mammals, the majority of cellular energy ultimately derives from progressive oxidation of simple organic molecules, with molecular oxygen being the terminal electron acceptor (117).

Because aerobic metabolism is not entirely efficient, reactive oxygen species (ROS), particularly superoxide $\left(\bullet \mathrm{O}_{2}{ }^{-}\right)$, are produced as its inevitable by-product; this occurs for an estimated $1 \%-2 \%$ electrons passing through the mitochondrial electron transport chain (2). Superoxide is also produced by other enzyme systems, for example, NADPH and xanthine oxidases, and normally is rapidly dismutated to produce hydrogen peroxide $\left(\mathrm{H}_{2} \mathrm{O}_{2}\right)$ by superoxide dismutases (e.g., $\mathrm{Cu} / \mathrm{Zn}-\mathrm{SOD}$ ) (35). Peroxide and superoxide are not themselves excessively toxic, since for example, the reaction of superoxide with other non-radicals is spin forbidden, but instead may react with nitric oxide $(\bullet N O)$ to produce the highly toxic peroxynitrite anion $\left(\mathrm{OONO}^{-}\right)$. Moreover, both superoxide and peroxide can undergo Fenton chemistry in the presence of poorly ligated transition metal ions to produce the extremely reactive hydroxyl free radical $(\bullet \mathrm{OH})$ (63). ROS production increases during hypoxia (14), and may also occur as a result of exogenous stresses such as ionizing radiation and auto-oxidizing xenobiotics (96). At physiological concentrations (nanomolar to low micromolar), intracellular $\mathrm{H}_{2} \mathrm{O}_{2}$ can reversibly oxidize redox-sensitive cysteine and methionine residues and in this context has been proposed to play an important signaling role, acting as a second messenger through via targeted inactivation of enzymes bearing active site cysteines, for example, phosphotyrosine phosphatases $(35,60)$. At higher concentrations, $\mathrm{H}_{2} \mathrm{O}_{2}$ oxidizes the glutathione pool and activates oxidative stress responses (19, 26), both through a rapid rerouting of cellular metabolism (42, 105) and through transcriptional responses, for example, oxidation of redox-sensitive cysteines in Forkhead box protein $\mathrm{O} 4$ (FOXO4) facilitates the formation of transcriptionally active complexes with p300/CBP acetyltransferase (22). Still higher concentrations of $\mathrm{H}_{2} \mathrm{O}_{2}$ become toxic due to induction of single- and double-stranded DNA breaks, oxidative decarboxylation of $\alpha$-ketoacids such as pyruvate, and irreversible denaturation of proteins through oxidation and carbonylation of arginine, proline, lysine, and threonine residues (96).

To protect themselves from this continual barrage of ROS production, cells invest in antioxidant systems such as 
catalase, methionine sulfoxide reductase (MSR) glutathione peroxidase (GPX), and peroxiredoxin (PRX). These antioxidant systems in turn require a steady supply of reducing equivalents, for example, $\mathrm{NAD}(\mathrm{P}) \mathrm{H}$ and reduced glutathione (GSH). In addition, very many cellular processes are dependent upon the local availability of appropriately reduced or oxidized redox co-factors, for example, fatty acid synthesis requires NADPH (117) and sirtuin-mediated lysine deacetylation is dependent upon $\operatorname{NAD}^{+}(3,106)$. Moreover, the extracellular environment and its contiguous cellular compartments such as the endoplasmic reticulum (ER) exist in a more oxidized state than the cytosol, and thus transport processes between compartments place an additional demand on cellular redox resources. As a consequence therefore, the intracellular milieu exists in a state of perpetual dynamic flux between oxidizing and reducing equivalents, facilitated by simultaneous redistributions of traffic through metabolic networks, with the whole being subject to exquisitely fine regulation to achieve compartment-specific redox homeostasis $(6,57,87)$. When these systems fail to adequately deal with acute oxidative insults, then cell death, apoptotic or necrotic, is inevitable. Moreover, chronic oxidative stress and misregulation of redox balance underlie several theories of aging (34) and, like circadian dysregulation, are associated with a large number of diseased states including many cancers, type II diabetes, and cardiovascular disease $(38,65,107,138)$.

\section{Compartmentalization of Metabolism}

To prevent wasteful mutually antagonist processes, many metabolic processes are separated into different spatial compartments, for example, during intense muscular activity anaerobic glycolysis results in the export of lactate from skeletal muscle that is converted back to glucose through gluconeogenesis in the liver. Within individual cells, redox balance substantially varies between different cellular compartments concomitant with function, for example, in the secretory pathway, correct disulfide bind formation and folding of proteins destined for the extracellular environment is dependent upon the more oxidized GSH:GSSG ratio found in the ER lumen $(13,52)$. Likewise, processes such as cytosolic fatty acid synthesis are spatially segregated from antagonistic processes, such as mitochondrial $\beta$-oxidation, thus avoiding energetically expensive, futile cycles (117). Similar advantages appear to accrue from separating mutually antagonist processes in time, for example, during the yeast metabolic oscillation, where periods may vary from $\sim 40 \mathrm{~min}$ to $>10 \mathrm{~h}$ depending on the strain and culture conditions, biochemically incompatible catabolic and anabolic processes are divided between oxidative and reductive phases $(15,129)$. In mammals, a great deal of metabolic temporal segregation occurs over the day/night cycle, a well-known example being the liver's usual nightly switch from a daily regime that favors glycogen storage and glycolysis, to glycogenolysis and gluconeogenesis (being anticipated by a circadian upregulation of gluconeogenic transcripts) that is required to maintain blood glucose levels throughout the habitual fast period during sleep (1).

At every level of biological scale in mammals, from the whole organism down to the activities of enzymatic pathways, a significant proportion of metabolism is observed to be under circadian regulation-leading to the prevailing view that the biological clock drives metabolic rhythms. As will be discussed, however, a growing number of observations suggest the converse also to be true-that at each level of scale, metabolism regulates circadian timekeeping. In a cycle, it is often impossible to separate cause from effect, and this review will therefore consider the evidence supporting a recent third interpretation that metabolic cycles and circadian oscillations are so inextricably linked that little meaningful distinction can be made between them (4).

Fundamentally however, it is important to bear in mind probably the most important recent advance in understanding the mammalian circadian clock-that circadian timekeeping is at root a cellular phenomenon being readily observable in isolated cells and tissues cultured in vitro (135, 136, 141). Thus, every aspect of circadian behavior and physiology in whole animals has its genesis in the biology of the cell and the signaling that takes place between cells. As we find more and more aspects of cell biology and endocrinology to be circadian regulated, Bernard's milieu intérieur expands into a temporal homeostasis where physiological set points approximate a sine wave with a frequency approximately equal to 1 day (also see Fig. 1).

\section{Systemic Control}

In mammals, the suprachiasmatic nucleus ( $\mathrm{SCN})$ of the hypothalamus was considered the center of mammalian timekeeping until quite recently, since its surgical ablation in rodents abolishes circadian rhythms in body temperature, behavior, and the secretion of endocrine factors such as cortisol and melatonin (137). Moreover, a surgical graft of fetal SCN tissue onto SCN-ablated rodents confers the circadian behavioral phenotype of the donor strain $(66,104)$. Organotypic SCN slices remain viable for many months in vitro and maintain many of their in vivo circadian properties, for example, robustness, accuracy, and interneuronal coupling, and have therefore been an attractive model for investigating clock mechanism in a reduced, but physiologically relevant context. Recent observations, however, have revealed that the accuracy and robustness of timekeeping in dissociated SCN neurons are poor compared with rhythms from intact SCN slices or whole animals [cycle-to-cycle period variation of $\sim 2 \%, 3 \%$, and $9 \%$ in mice, slices and neurons, respectively (46)] and thus it is generally accepted that the SCN's remarkable timekeeping fidelity is an emergent property of its interneuronal circuitry, rather than being anything special to its component neurons $(125,135,136,141)$. In vivo, the SCN is therefore understood to constitute the foremost center for coordinating rhythms generated by innumerable, ostensibly subordinate, cellular clocks distributed throughout the rest of the body. Comprising $\sim 20,000$ neurons, the SCN employs both humoral factors and axonal projections to other brain regions to maintain stable phase relationships between peripheral tissues (137). Sited above the optic chiasm, a proportion of SCN neurons have excitatory glutamatergic innervations from the retinohypothalamic tract, receiving photic cues from photoreceptor cells, and non-photic signals from the brainstem (e.g., neuropeptide $\mathrm{Y}$ [NPY], 5hydroxytryptamine [5-HT]) $(11,78)$. Put simply, the SCN is a specialized timekeeping locus that integrates multiple inputs to maintain its oscillation and in turn populates a diversity of output pathways to convey temporal cues appropriate to each 
target site. For some excellent recent reviews of the SCN, readers are directed toward $(17,137)$, as well as Gillette and Wang in this Forum.

The SCN regulates numerous aspects of rhythmic metabolism. This can occur directly via neuronal or humoral signaling, and indirectly through control of behavior. An oftcited example of the former is the SCN-driven circadian regulation of the hypothalamic-pituitary-adrenal axis, resulting in the daily surge of plasma corticosterone prior to the wake period, priming the body for activity (58). More recently, it was demonstrated that SCN-regulated factors in serum drive daily rhythms of serum response factor activation in the liver (39). Many other aspects of rhythmic metabolism are indirectly influenced by the $\mathrm{SCN}$, since in the absence of competing stimuli the SCN regulates sleep propensity, which in turn influences fasting/feeding times that in turn dictates nutrient uptake (where food is available), and thus indirectly induces rhythms in all of the well-characterized acute responses to food intake for example, the diurnal rhythm in plasma leptin in humans is largely driven by meal timing and abolished by long periods of fasting $(32,120)$. It is important to note, however, that control of rhythms in peripheral tissues can be wrested from the SCN under situations such as restricted feeding, that is, fed ad libitum or exclusively at night, on a standard $12 \mathrm{~h}: 12 \mathrm{~h}$ light:dark cycle mice feed mostly during the subjective night but when food is restricted to the light phase, the phases of gene expression in peripheral tissues and the rhythm in core body temperature, gradually shift until after $\sim 1$ week they are in antiphase (21). Under these conditions the phase of SCN activity continues to track the light:dark cycle, and importantly in SCN-ablated mice the rate of this food entrainment is increased. When these types of experiments are performed in constant darkness, the phase of behavioral activity also shifts to anticipate the time of feeding and these daily rhythms of food anticipatory behavior persist for several cycles even when food is withheld (93). An anatomical locus for this "food entrainable oscillation" remains the subject of great debate and controversy (23), but certainly does not require involvement of the SCN or any of the identified "clock genes" (121). The phenomenon itself serves as an important reminder that due to the SCN's highly specialized nature, its constituent neurons normally comprise the foremost of cellular oscillators as regards organismal timekeeping function and entrainment to lighting cues, but that timekeeping persists in peripheral tissues in its absence (125), and that to understand the link between circadian rhythms, metabolism, and redox it is necessary to venture inside the cell.

\section{Cellular Clocks}

As any engineer will agree, the simplest way to generate an oscillation is through delayed negative feedback. For it not to damp out some element of positive feedback is also required (124). Informed largely by forward and reverse genetic screens, until recently models of cellular timekeeping largely focused on transcriptional/translational feedback mechanisms whereby positive activators (e.g., BMAL1/ARNTL and Circadian Locomotor Output Cycles Kaput [CLOCK]) bind to commonly occurring regulatory promoter elements (e.g., E-boxes) of many circadian-regulated output genes, including those that encode transcriptional "clock gene" repressors, for example, PERIOD1/2(PER1/2) and CRYPTOCHROME1/2
(CRY1/2), facilitating transcriptional activation around anticipated dawn. The repressor proteins are processed posttranslationally, and they eventually accumulate to form complexes later in the day, prior to nuclear entry around anticipated dusk. At night, these repressive complexes inhibit CLOCK/BMAL1-driven transcription in many "clockcontrolled gene" (CCG) promoters, including their own, and are then progressively degraded. This relaxes the transcriptional repression before dawn, licensing the cycle to begin anew (110). Accessory feedback circuits, such as the one mediated by the repressive REV-ERB $\alpha / \beta$ and activating $\operatorname{ROR} \alpha / \gamma$ nuclear receptors that act upon RAR-related orphan receptor elements (ROREs) within the Bmal1 promoter, lend additional robustness to this "core" transcriptional circuit, and regulating expression of other downstream CCGs, either directly or via tissue-specific output regulators such as E4BP4 $(4,130)$ see Figure 2.

In principal, combinatorial action of different circadianregulated promoter sequences is sufficient to license transcription at any conceivable phase over the 24-h cycle (49, 72). As more clock gene transcription factors and their cocomplexes have been identified, sophisticated models of cycling transcriptional activation/repression with concomitant chromatin remodeling/epigenetic modification have been developed and account for many experimental observations $(4,27,130)$. Microarray studies have shown that the identity of cycling mRNA transcripts enormously varies from tissue to tissue (28), presumably in a fashion appropriate to organ function, although the picture is complicated by proteomics investigations that have revealed no predictable correlation between whether a given mRNA transcript is rhythmic or at constant levels, compared with whether the encoded protein levels oscillate or not $(24,108)$. In addition, in mouse liver assayed over the circadian cycle in constant darkness, only $\sim 20 \%$ of mRNA cycling genes are driven by de novo transcription suggesting that the lion's share of rhythmic circadian regulation of gene expression takes place post-transcriptionally $(54,68,69,77,90)$ and post-translationally $(45,51,79,108$, 119). Indeed, both the stability and subcellular localization of all the core "clock proteins" is controlled by a number of ubiquitous eukaryotic kinases and phosphatases, for example, CK1, CK2, GSK3, PP1, AMPK, and so on $(45,100)$.

The observation that certain genes are quite consistently expressed with a circadian rhythm (in vivo and in vitro) has enabled the widespread application of real-time bioluminescent reporters for timekeeping, whereby firefly luciferase expression is driven by circadian regulated promoter elements, enabling non-invasive, long-term recordings of rhythmic bioluminescence to be made $(91,139)$. Using reporters such as the PERIOD2::LUCIFERASE (PER2::LUC) knock-in mouse (in which luciferase cDNA was introduced in-frame to the final exon of the genomic PERIOD2 locus resulting in a rhythmically expressed fusion protein) has enabled single-cell timelapse imaging of molecular circadian rhythms in culture (141). Rhythms of bioluminescence from isolated primary fibroblast cultures from such mice persist for at least 6 weeks, although they slowly desynchronize from one another, and so it can safely be inferred that since the mammalian circadian cellular clock does not damp out, it must incorporate both positive, and delayed negative, feedback (81).

Notwithstanding the success of such transcriptionaltranslational feedback loop (TTFL) models, there exist a 

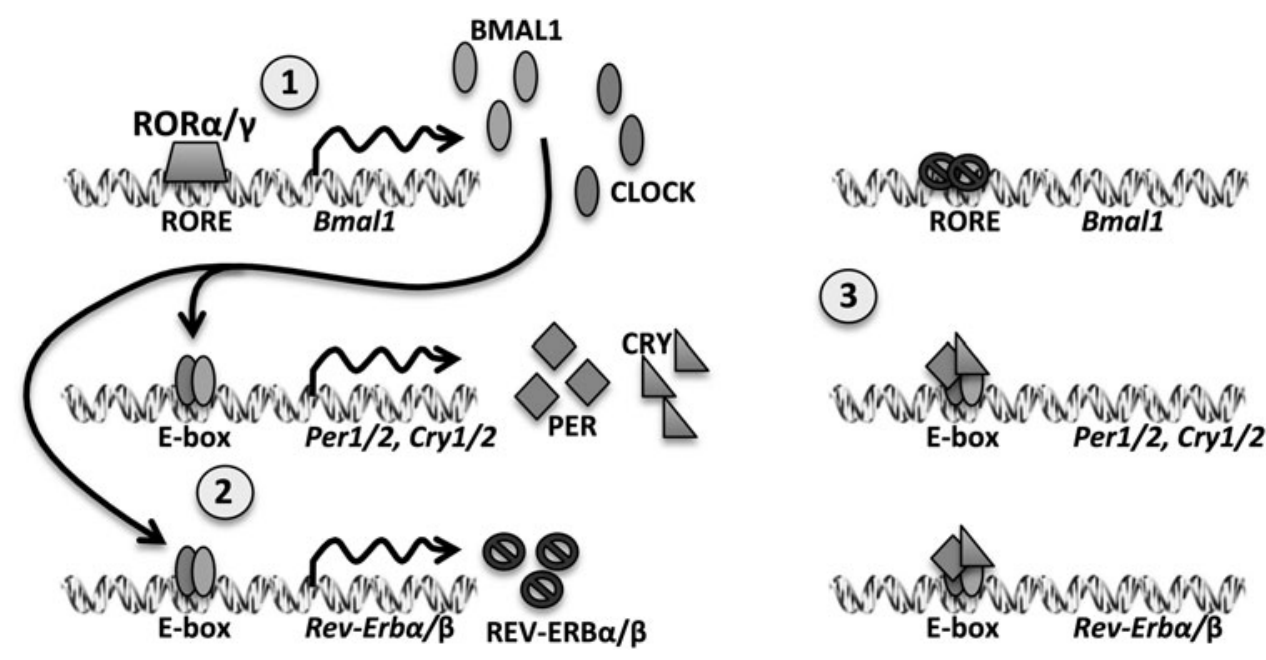

FIG. 2. A simplified and generalized schematic of the mammalian circadian transcriptional-translational feedback loop. [1] $\mathrm{ROR} \alpha / \beta$ activates expression of Bmal1, a bHLH transcription factor. [2] BMAL1 protein heterodimerizes with a partner, such as CLOCK, at promoter sites containing E-box consensus motifs (CACGTG) to activate expression of myriad output genes including repressors Period1/2, Cryptochrome1/2, and Rev-Erb $\alpha / \beta$, which are subject to a series of post-translational modifications (not shown) that license them for nuclear entry later in the cycle. [3] PER and CRY repress the activity of BMAL1 complexes, inhibiting transcription at their cognate promoter elements and other "clock-controlled genes". REV$\mathrm{ERB} \alpha / \beta$ repress expression of Bmal1 and at other loci that are regulated by proximal-promoter elements containing the RORE consensus motif. The repressor protein mRNA and proteins are eventually targeted for proteasomal degradation allowing the cycle to begin afresh. This cycle occurs with a period of $\sim 24 \mathrm{~h}$. bHLH, basic helix-loop-helix; CLOCK, Circadian Locomotor Output Cycles Kaput; RORE, RAR-related orphan receptor element.

number of observations, which challenge whether cycling "clock gene" expression constitutes the mechanistic basis of cellular timekeeping, as opposed to being an important functional consequence of it. These are discussed in detail elsewhere $(45,53,73,100,103)$, but the paradigm that most recently encouraged alternative hypotheses was provided by a landmark series of experiments that investigated timekeeping in the cyanobacteria Synechococcus elongatus. In this simple prokaryote, a transcriptional-translational feedback model comprising the gene expression products of KaiBC (negative limb) and KaiA (positive limb) had been largely accepted as the basis of its circadian clock mechanism until it was shown that rhythms of KaiC phosphorylation persist for many days when nascent gene expression is abolished using inhibitors of transcription and translation (127). This was rapidly followed by the more striking observation that this phosphorylation rhythm could also be observed when the purified KaiA, B, and C proteins were incubated in vitro at the appropriate concentrations in the presence of ATP (95). It has now become largely accepted that the major contribution of transcriptional cycles to cyanobacterial timekeeping mechanism is to provide robustness to this post-translational oscillation, besides of course being the most prominent functional output from it $(103,126,146)$.

It might be argued that the biochemical clock in cyanobacteria represents a special case, since the experimental evidence supporting a transcriptional feedback-based mechanism in eukaryotes is compelling. This would be misleading, however, since the evidence supporting a transcriptional clock mechanism in S. elongatus was similarly compelling until its entirely post-translational oscillatory mechanism was reconstituted. Moreover, evidence supporting a purely posttranslational timekeeping mechanism in eukaryotic systems has existed for more than half a century $(122,123)$. To summarize a beautiful series of experiments performed in the macroscopic alga Acetabularia, Sweeney and colleagues observed that circadian rhythms of photosynthesis persist (over $>3$ days, under constant conditions) even when the cell's nucleus was removed and in the presence of inhibitors of gene expression, implying that the cellular oscillator must reside in the cytosol.

In a mammalian cellular context, experiments have been recently performed that point in the same direction. For example, Dibner et al. showed that bioluminescence rhythms in a mammalian cell line are relatively insensitive to global transcriptional inhibition (25), and this tends to undermine any model whereby the rate and timing of transcription play a primary role in determining cellular timekeeping capacity. In addition, we recently observed circadian rhythms of redox balance in isolated human red blood cells, maintained under constant conditions over several days in vitro (98). Mammalian erythrocytes are naturally anucleate-lacking any organelles, including the nucleus, mitochondria, or functional ribosomes, and are therefore incompetent to perform nascent gene expression. Moreover, it has been noted by many, the contribution that certain ubiquitous post-translational mechanisms make to circadian timekeeping, these being better conserved across the eukaryotes in their functional contribution to circadian timekeeping than any transcriptional component, for example, in addition to their other numerous cellular functions, casein kinase 1 and 2 appear to fulfil an essential clock role across a wide range of eukaryotic model organisms from mammals to flies, from fungi to algae $(83,85$, 99). Further, most genetic manipulations of transcription factor "clock genes" have relatively modest effects on the behavioral period of mice (rarely longer/shorter by $>10 \%$ ) 
but significantly, there are a handful of genetic lesions in which animals become behaviorally arrhythmic. The evidence that cellular oscillations cease under these conditions is not conclusive however, since the genetic lesions in question (e.g., Bmal1 ${ }^{-/-}$) may well be epistatic to the bioluminescent reporter (PER2::LUC) used to assess rhythmicity (100).

What is striking about the majority of circadian mutant mouse lines is that in most cases they exhibit strong metabolic phenotypes (8), for example, the Rev-Erb $\alpha / \beta$ and also $C r y 1 / 2$ homozygous double knockout mice $(16,132)$, and the Bmal1 $^{-/-}$knockout mouse (12) all exhibit profoundly disordered rhythms in behavior and dyslipidemia and impaired glucose homeostasis $(8,76,86)$, with the latter being a model for the $\beta$-cell dysfunction, metabolic syndrome, and diabetes (86). This is frequently interpreted to mean that rhythmic cycling of the transcriptional "core clock gene" circuitry is essential for metabolic homeostasis. There are significant differences between these three mouse models, however (142), and it is therefore difficult to establish the cause versus effect of losing the protein activity (all of which have established roles outside circadian timekeeping) from the effect of losing a "clock component", for example, the Bmal1"-knockout mouse exhibits an early aging phenotype that correlates with increased accumulation of ROS in many tissues, but this has not been observed for other clock gene mutants $(70,142)$. The possibility exists therefore that these "clock genes" instead represent a subset of cellular transcription factors whose activity is sensitive to circadian timing cues, and therefore may contribute to sustaining the cellular oscillation, but in addition mediate many other tissue-specific transcriptional responses and also respond to cues that facilitate their acute activation (100). Certainly, current data support other interpretations equally well, for example, one might argue that the activities of REV-ERB, CRY, and BMAL1 homologs are essential for different aspects of normal metabolic regulation, and thus in their absence cellular metabolism becomes dysregulated with concomitant effects on gross physiology, and with circadian timekeeping being disrupted as an indirect consequence. In this vein, it is interesting to note that the transcription factor NRF2, (a so-called master antioxidant regulatory factor), is transcriptionally regulated by BMAL1 and that the observed $\beta$-cell dysfunction and early aging phenotype (70) in the BMAL1 knockout mouse has been attributed to an accumulation of ROS due to mitochondrial uncoupling (80). Of further relevance are some recent observations that have employed undifferentiated embryonic stem cells (ESCs). ESCs were previously considered not to possess any intrinsic timekeeping because although clock gene transcription factors such as BMAL1 are expressed, their levels do not exhibit circadian cycles until after differentiation. Paulose et al., however, report a self-sustained circadian rhythm in ESC uptake of 2-deoxyglucose prior to, and following, differentiation (102). Similar to the findings in erythrocytes, this suggests that circadian rhythms in metabolism (in this case glucose utilization) may persist in the absence of gene expression (cycling or otherwise), but does not satisfactorily address whether transcriptional cycles (when they are present) may run independently from metabolic oscillations, or are coupled with them. It would be most informative to investigate how ESC metabolic rhythms are perturbed in cells from one or more of the arrhythmic mouse models mentioned above.
Essentially then, in answer to the question "why, mechanistically, is the period of this cellular oscillation $\sim 1$ day" it is not clear that we understand the system sufficiently well that an answer can be given in terms of concentrations, dissociation constants, and rate constants-as is the case for the reconstituted KaiABC oscillation in cyanobacteria. We clearly do know a number of relevant mechanisms, however, and this has led many to the parsimonious view that regardless of explicit mechanism, rhythmic regulation of gene expression clearly plays an essential role in co-ordinating the normal temporal regulation of cellular metabolism, physiology, and behavior in experimental animals, and by inference humans.

\section{Biological Clocks and Metabolism- the Liver as a Case Study}

The majority of the last 50-60 years of circadian research can be placed somewhere on a spectrum between attempts to address two separate questions, namely "what is the basis of circadian timekeeping" and "what are the consequences of circadian timekeeping?" As a result most of what is currently understood about the interactions between circadian rhythms, redox balance, and metabolic regulation also fall somewhere between the two extremes. It is important therefore to appreciate the sheer scale of metabolism that exhibits circadian regulation - in this instance, the liver makes an excellent case study because due to its abundance it has become the organ of choice with which to test new "-omics" techniques over circadian timescales. See Table 1.

This leaves one with the overwhelming impression that the humble hepatocyte is simply not the same cell between day and night. One should exhibit caution before drawing more general conclusions from these studies, however, since it is likely that many of the specific findings are particular to the biology of the liver-important though that clearly is for understanding liver disease and metabolic disorders. Moreover, the majority of these studies inform us about how the heterogeneous cellular assemblage in the liver behaves when in receipt of rhythmic cues from the rest of the body, rather than about cell-autonomous timekeeping mechanisms per se. This latter point is elegantly highlighted by work from Kornmann et al., who engineered mice harboring a conditionally active liver clock, whereby constitutive overexpression of REV-ERB $\alpha$ in hepatocytes resulted in repression of BMAL1 expression, but only in the absence of doxycycline. In the presence of doxycycline the transgene remained repressed, resulting in normal transcriptional rhythms. By using microarrays to compare mouse livers harvested over a circadian cycle from animals with or without doxycycline, the striking result was that $\sim 9 \%$ of cycling transcripts remained rhythmic in animals lacking a functional hepatic transcriptional clock circuitry. Among these genes was PERIOD2, whose rhythms at the protein and transcript level were barely affected, suggesting that the expression of this "essential clock gene" is normally under systemic, and local, control in hepatocytes. These findings were extending in work by Vollmers et al., who observed that the number of rhythmic mRNA transcripts in liver dramatically fell when mice were fasted (133). This may reflect a starvation response, however, since equivalent experiments performed using Met murine hepatocytes (cultured under constant conditions in vitro) identified >1000 oscillating transcripts (including Period2, and enriched for metabolic 
Table 1. A Summary of Circadian-Regulated Metabolically Relevant Processes in Rodent Liver

\begin{tabular}{|c|c|c|c|}
\hline Under investigation & Method/Approach & Observation & Reference \\
\hline $\begin{array}{l}\text { Key intermediates of } \\
\text { carbohydrate } \\
\text { metabolism and } \\
\text { redox balance }\end{array}$ & $\begin{array}{l}\text { Enzymatic assays of } \\
\text { steady-state } \\
\text { metabolite levels }\end{array}$ & $\begin{array}{l}\text { Diurnal variation in metabolic pathways } \\
\text { for example, glycolysis, purine, } \\
\text { metabolism, Krebs cycle, NADP }{ }^{+} \text {: } \\
\text { NADPH ratio }\end{array}$ & (59) \\
\hline "Clock gene" expression & $\begin{array}{l}\text { Northern and western blot, } \\
\text { bioluminescence }\end{array}$ & $\begin{array}{l}\text { Circadian regulation of promoter activity, } \\
\text { mRNA level, protein level, and } \\
\text { localization }\end{array}$ & $(7,79,140)$ \\
\hline mRNA levels & Microarray & $\begin{array}{l}\sim 10 \% \text { transcriptome is rhythmically } \\
\text { expressed }\end{array}$ & $(1,101)$ \\
\hline Cytosolic protein levels & $\begin{array}{l}\text { 2D-DIGE and mass } \\
\text { spectrometry }\end{array}$ & $\begin{array}{l}20 \% \text { abundant soluble liver proteins } \\
\text { are rhythmically expressed, } \\
\text { approximately half exhibit rhythmic } \\
\text { mRNA }\end{array}$ & $(108)$ \\
\hline Glucose metabolism & $\begin{array}{l}\text { Pharmacological and } \\
\text { conditional genetic } \\
\text { manipulation }\end{array}$ & $\begin{array}{l}\text { Glucose uptake/export, anabolism/ } \\
\text { catabolism, storage and intracellular } \\
\text { insulin/glucagon signaling are } \\
\text { clock-controlled and required for 24-h } \\
\text { glucose homeostasis }\end{array}$ & $(71,74-76,144)$ \\
\hline $\begin{array}{l}\text { Post-transcriptional } \\
\text { regulation of gene } \\
\text { expression }\end{array}$ & Various & $\begin{array}{l}\text { Much of rhythmic protein expression is } \\
\text { regulated at the level of mRNA stability, } \\
\text { translation, and global ribosomal } \\
\text { biogenesis }\end{array}$ & $(54,69)$ \\
\hline $\begin{array}{l}\text { Unfolded protein } \\
\text { response }\end{array}$ & $\begin{array}{l}\text { Northern and western } \\
\text { blot, RT-PCR }\end{array}$ & $\begin{array}{l}\text { A circadian-regulated } 12 \mathrm{~h} \text { rhythm in the } \\
\text { ER IRE } 1 \alpha \text { pathway that is required for } \\
\text { normal lipid metabolism }\end{array}$ & $(18)$ \\
\hline $\begin{array}{l}\text { SIRT1 activity/NAD }{ }^{+} \text {- } \\
\text { salvage pathway }\end{array}$ & Various & $\begin{array}{l}\mathrm{NAD}^{+} \text {levels are a circadian output } \\
\text { leading to rhythmic regulation of SIRT1 } \\
\text { deacetylase activity (rhythmic input) }\end{array}$ & $(3,94,106)$ \\
\hline Autophagy & Various & $\begin{array}{l}\mathrm{C} / \mathrm{EBP} \beta \text { is rhythmically expressed in the } \\
\text { liver and drives rhythmic autophagy }\end{array}$ & $(84)$ \\
\hline $\begin{array}{l}\text { Steady state metabolite } \\
\text { levels }\end{array}$ & Global metabolomics & $\begin{array}{l}20 \% \text { of detected metabolites exhibit } \\
\text { diurnal rhythms. Most nucleotide } \\
\text { biosynthesis is also circadian }\end{array}$ & $(30,37)$ \\
\hline ROS production & Various & $\begin{array}{l}\text { Rhythmic PRX over-oxidation, cytochrome } \\
\text { P450 activity and lipid peroxidation }\end{array}$ & $(31,36,118)$ \\
\hline $\begin{array}{l}\text { Epigenetic regulation } \\
\text { of gene expression }\end{array}$ & $\begin{array}{l}\text { ChIP-seq, nascent seq, } \\
\text { RNA-seq }\end{array}$ & $\begin{array}{l}\text { Circadian modulation of RNA polymerase } \\
\text { II recruitment and chromatin remodeling } \\
\text { occur on a genome-wide scale. Many } \\
\text { loci exhibit rhythmic histone marks and } \\
\text { circadian binding of transcription factors }\end{array}$ & $\begin{array}{l}(54,68,69 \\
\quad 77,90,131)\end{array}$ \\
\hline Protein acetylation & $\begin{array}{l}\text { Quantitative mass } \\
\text { spectrometry }\end{array}$ & $\begin{array}{l}\text { Many cytosolic and mitochondrial enzymes } \\
\text { are rhythmically acetylated }\end{array}$ & $(89)$ \\
\hline
\end{tabular}

ChIP-seq, chromatin immunoprecipitation sequencing; DIGE, difference in-gel electrophoresis; ER, endoplasmic reticulum; PRX, peroxiredoxin; ROS, reactive oxygen species; RT-PCR, reverse transcription polymerase chain reaction; SIRT1, SIRTUIN 1.

enzymes) implying that hepatocyte clocks respond to, but do not require, systemic cues to oscillate (5).

\section{Cellular Circadian Metabolic and Redox Oscillations}

A point worth emphasizing is that, in the hepatocyte example above, PERIOD2 activity can equally be described as a core component of the cellular oscillation, a regulator of its outputs (CCGs), and a mediator of inputs into it. This frames the general problem of trying to delineate causation in any biological oscillation, especially in the context of interactions with metabolism and redox, since a cycle has no beginning or end. In vivo, each mammalian cell is an autonomous oscillator that, by virtue of its normal biological function being modulated by cell-intrinsic circadian cycles, contributes to systemic rhythms, which during another part of the cycle or in a dif- ferent cell type, may directly determine the phase and/or amplitude of the oscillation. To rephrase: a rhythmic output at one time or location often constitutes an important rhythmic input at another time or location. In addition to rhythms in endocrine signaling, which directly drive rhythms of intracellular metabolism and ROS production (64), and rhythms in body temperature, which have also been shown sufficient to entrain the phase of peripheral (non-SCN) tissues (116), a significant proportion of serum metabolites themselves exhibit a circadian rhythm in both mouse and humans $(20,61$, 92). For example, using a 40-h constant routine protocol to minimize potentially confounding variables such as the timing of sleep and food intake, Dallmann et al. observed that $\sim 15 \%$ of all identified metabolites in plasma were under circadian control, this included critical regulators of intracellular metabolism such as heme $(20,128)$. Moreover, Blanco 
et al. observed an approximately twofold diurnal variation in the GSH/GSSG and Cys/CySS redox couples in serum (10), implying that even the basal antioxidative capacity in the blood varies between day and night.

It should be briefly mentioned that the circadian-regulated hormone melatonin has also been proposed to play an antioxidant role (88), but its concentration in plasma and tissue $(<1 \mathrm{n} M)$ is so low compared with established antioxidant mechanisms, for example, serum ascorbate $(\sim 50 \mu M)$, cytosolic GSH (4-5 mM), that we consider it unlikely to make any significant contribution.

In the face of such complexity it is appealing to reduce the system to a simpler level of abstraction, that is, the cell, at which we might more readily grasp how circadian rhythms interact with cellular metabolism, and thence build back up to higher levels of biological scale. Unfortunately, significantly fewer observations have been made that directly address which aspects of cellular metabolism exhibit persistent circadian rhythms in cell culture, but those that exist are intriguing. An appropriate example might be the circadian cycles observable in the oxidation state of the PRX proteins.

The PRXs are small ( 20-25 kDa), ubiquitously expressed antioxidant proteins, which like SOD, catalase, and GPX are found in virtually all aerobic organisms (44). They share a common catalytic mechanism whereby reducing peroxide, the catalytic active site cysteine residue $\left(\mathrm{Cys}_{\mathrm{P}}\right)$ is oxidized to a sulfenic acid (Cys-SOH), which then forms a disulfide bond with the resolving Cys residue $\left(\mathrm{Cys}_{\mathrm{R}}\right)$ on the opposing dimer $(35,112)$. The work of Rhee et al. has revealed that the electrostatic environment surrounding the active site cysteine confers upon it a particularly low $\mathrm{pK}_{\mathrm{a}}(\sim 5-6)$ meaning it largely exists in the thiolate state $\left(\mathrm{Cys}^{-} \mathrm{S}^{-}\right)$, which in addition to their high selectivity and abundance $(\sim 0.1 \%-1 \%$ of total cellular protein) make the PRXs the primary sink for endogenously derived peroxides ( $\mathrm{ROOH}$ ) (35). At physiological levels of $\mathrm{H}_{2} \mathrm{O}_{2}$, this results in singly or doubly disulfide-linked PRX dimers that normally are reduced by the thioredoxin system in a fashion that ultimately consumes NADPH, much like the GSH/GRX system. In a subclass of PRXs, namely the classical 2-Cys PRXs, a small fraction of the enzyme becomes catalytically inactivated through substrate-mediated over- or hyperoxidation of $\mathrm{Cys}_{\mathrm{P}}$ to the sulfinic or sulfonic acid forms (Cys-SO $\mathrm{S}_{2}$ ). The sulfinic form has been demonstrated, in numerous contexts, to reversibly occur under physiological conditions before being recycled to the ground state through an ATP-dependent reduction by sulfiredoxin (111).

Several years ago an unbiased screen of the mouse hepatic circadian protein revealed a member of the peroxiredoxin protein family (PRX6) to be rhythmically expressed but also undergoing an anti-phasic post-translational modification (108). We subsequently observed this to also be true for other PRX family members $(31,98)$. Using a polyclonal antibody that recognizes the $\mathrm{SO}_{2 / 3}$ modification within the conserved active site of the 2-Cys PRXs, we observed circadian rhythms of PRX over-oxidation in cell culture using NIH 3 T3 fibroblasts and mouse embryonic fibroblasts (MEFs) (98), and in human U2OS cells (J.S. O'Neill, unpublished). MEF PRX-SO $2 / 3$ rhythms could be entrained by temperature cycles $\left(32^{\circ} \mathrm{C} /\right.$ $37^{\circ} \mathrm{C}$ ), and were also observed in a CRY $1 / 2$ homozygous null background. Crucially, however, the rhythms in the latter, transcriptionally arrhythmic mutant line were clearly perturbed in their phase of entrainment relative to wild-type, apparently displaying a much longer free-running period ( $\sim 36 \mathrm{~h})$. More recently, very similar results have been observed in time courses performed under constant conditions across a wide range of circadian model systems including organotypic SCN slice (mouse), Ostreococcus tauri (alga) Arabidopsis thaliana (plant), Caenorhabditis elegans (nematode), Drosophila melanogaster (fly), Neurospora crassa (fungus), S. elongatus (cyanobacteria), and Halobacterium salinarum (archaea). Rhythms of PRX oxidation were consistently observed in the respective wildtype and in long period or arrhythmic clock mutants. Again in the arrhythmic samples, PRX oxidation rhythms were detectable but clearly perturbed compared with wild-type. Critically, in rhythmic mutants displaying a long circadian period, the period of this metabolic rhythm, reported by PRX oxidation, was similarly lengthened $(31,99)$.

The converse experiments have also been performed with the result that PRX knockout (31), knockdown (143) or overexpression (J.S. O'Neill, unpublished) does tend to affect bioluminescently-reported circadian rhythms, but with the specific effect and its size substantially varying depending on the context for example, in an unbiased genome-wide RNAi screen performed using human U2OS cells, knockdown of PRX2 and PRX4 resulted in a long-period phenotype, whereas short interfering RNAs directed against PRX3 and PRX5 dampened the amplitude. This variation should not be surprising given the partially redundant nature of the PRX family (there exist six genetically encoded isoforms in humans and mice), within the wider repertoire of cellular antioxidant systems-especially bearing in mind their different subcellular localizations and functional specializations. So while interference with the basal antioxidant capacity of the cell will clearly have pleiotropic effects, it seems that one of these is to perturb cellular circadian timekeeping. In support of this interpretation, the same RNAi screen revealed a much stronger long period phenotype following knockdown of $\mathrm{Cu} / \mathrm{Zn}$ SOD1 (143), which of course produces the majority of cytosolic $\mathrm{H}_{2} \mathrm{O}_{2}$.

This daily cycle in PRX-oxidation was also readily observable in isolated erythrocytes, incubated for several days in vitro at $37^{\circ} \mathrm{C}$ in a minimal buffer. Importantly, the phase of the oscillation could be entrained using temperature cycles, and was observed to be temperature-compensated-thus conforming to the strict definition of a circadian rhythm.

Unlike most mammalian cells where the majority of ROS derive from "leakage" from mitochondrial electron transport chains, the majority of superoxide produced in a red blood cell derives from auto-oxidation of hemoglobin $(\mathrm{Hb})$, forming inactive met-hemoglobin (metHb), which is reduced back to $\mathrm{Hb}$ by NADH methemoglobin reductase (cytochrome-b5 reductase, the major pathway), NADPH methemoglobin reductase (minor pathway), and to a lesser extent the ascorbic acid and glutathione enzyme systems (67). $\mathrm{Hb}$ is a tetramer composed of two identical $\alpha \beta$ dimers, and in this state its four heme-bound irons cooperatively react with oxygen to facilitate its essential role in gas transport. The dissociation constant for the tetramer is $\sim 0.2 \mu \mathrm{M}$, whereas $\mathrm{Hb}$ concentration in red blood cells approaches $5 \mathrm{mM}$ (41), and so the vast majority of $\mathrm{Hb}$ in cells exists as cooperative tetramers. This dissociation constant has been shown to vary as a function of anion concentration (e.g., $\mathrm{Cl}^{-}, \mathrm{OH}^{-}$) (41) and moreover, $\mathrm{Hb}$ dimers, which bind $\mathrm{O}_{2}$ non-cooperatively (47), display a $\sim 13-$ fold higher auto-oxidation rate than tetrameric $\mathrm{Hb}(41)$. We 
therefore hypothesized that the rhythm in ROS generation in isolated erythrocytes, detected by PRX-oxidation, might be attributable to a rhythm in the $\mathrm{Hb}$ tetramer/dimer ratio (and thus metHb formation rate) due to some underlying rhythm in the ionic composition of the cytosol. This would lead in turn to a rhythm in the reducing equivalents NADH and NADPH necessary for reduction of metHb. This hypothesized rhythm in $[\mathrm{NAD}(\mathrm{P}) \mathrm{H}]$ was subsequently observed to be the case, and using an indirect report of $\mathrm{Hb}$ multimeric state (intrinsic frontface fluorescence) we also observed 24-h rhythms over several days, and a low amplitude oscillation in cellular ATP levels (98)-see Figure 3.

While these observations provide a satisfactory explanation for the observed rhythm in PRX-oxidation, they in no way account for why its period is $\sim 24$-h nor what is driving the modulation of $\mathrm{Hb}$ multimeric state. It is interesting to note, however, that mammalian cellular circadian redox oscillations do not appear to be restricted to erythrocytes, since rhythms in the redox balance of the glutathione and ascorbic acid system were subsequently observed in organotypic SCN slices (134). Further, earlier studies that employed isolated human platelets, also anucleate, similarly detected cellintrinsic circadian rhythms in the GSH:GSSG ratio.

Taken together, these findings imply that there is a circadian rhythm in cytosolic redox balance that is observed across the domains of life. It is modulated by PRX proteins but is not dependent upon them. It normally couples with cycles of gene expression, and is affected by genetic perturbation, but does not require nascent gene expression, cycling or otherwise. These observations also suggest either a cell-intrinsic rhythm in ROS production, or in the generation of reducing equivalents [as is the case in the $\mathrm{NAD}^{+}$salvage pathway (106)] or, most likely, both. If these inferences are correct, there exist two plausible interpretations: either there exists some unidentified, underlying and ancient metabolic oscillation whose period is circadian, which remains deeply embedded in cellular biology, from single-celled organisms to humans $(31,100)$; or else there has occurred a remarkable evolutionary convergence upon circadian regulation of redox balance to facilitate temporal segregation of mutually antagonistic metabolic processes. In the absence of further experiments, or a time machine, these cannot be distinguished for the time being.

\section{Metabolic Effects on Cellular Timekeeping}

If circadian rhythms in cellular metabolism and redox balance go beyond being epiphenomena, then there must exist functional consequences for the cell. There must, for example, be pathways by which changes in cellular metabolism communicate with the nucleus to elicit changes in gene expression. Some supporting evidence certainly exists, for example, the period of cellular rhythms in fibroblasts varies as

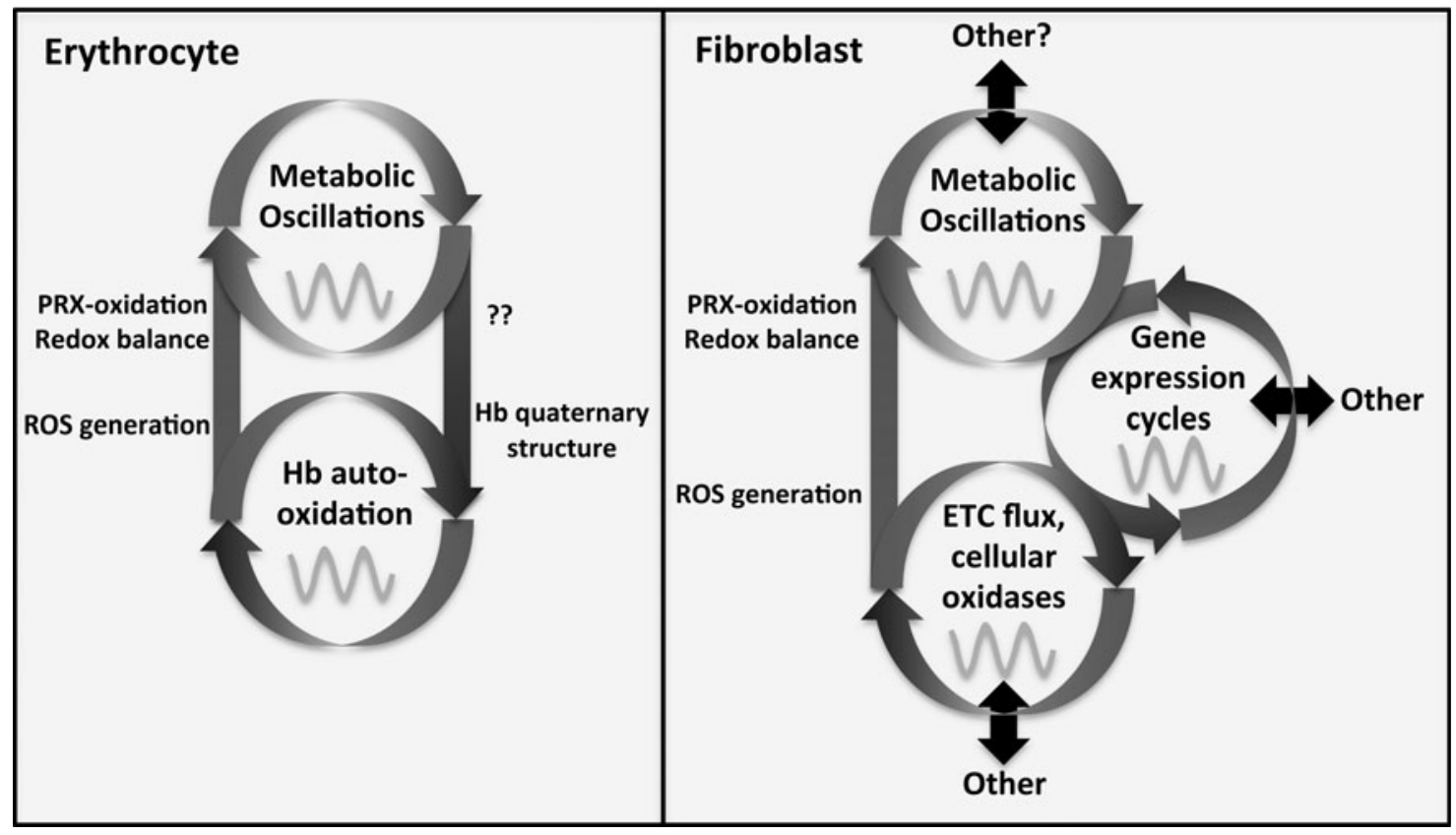

FIG. 3. A cartoon comparing rhythms of PRX-oxidation between erythrocytes and fibroblasts. In isolated erythrocytes, rhythms of PRX oxidation appear to result from cycles of increased ROS generation due to changes in the proportion of dimeric $\mathrm{Hb}$. The resulting rhythm in metHb formation is presumed to be responsible for the observed cycles in the reducing equivalents $\mathrm{NAD}(\mathrm{P}) \mathrm{H}$. Erythrocytes are an extremely reduced system, containing no organelles and lacking the capacity for nascent gene expression. Fibroblasts are a popular model system for cellular rhythm investigations, which also exhibit cellautonomous rhythms ROS generation, as determined by PRX oxidation, but in the midst of a far more complex intracellular environment. Possessing mitochondria, it is presumed that the majority of ROS generation results from rhythmic regulation of mitochondrial metabolism (although the contribution of other cellular oxidases remains to be established). There is evidence for coupling between metabolic oscillations and gene expression cycles, and there are established pathways, for example, NRF2, connecting nuclear gene expression with flux through the mitochondrial electron transport chain (ETC). These systems reciprocally regulate with numerous other cellular systems. Hb, hemoglobin; metHb, met-hemoglobin; PRX, peroxiredoxin; ROS, reactive oxygen species. 
a function of glucose concentration in the extracellular media (75), whereas an acute pulse of high glucose can entrain its phase (48). Moreover, RNAi knockdown of numerous components within the insulin-signaling and other metabolic pathways, elicits a wide range of robust effects on cellular rhythms in U2OS cells (144). Also, while it has not yet been demonstrated in mammalian cell culture, as it has in flies (145), it is highly likely that rhythmic generation of ROS leads to a cell intrinsic rhythm in sensitivity to oxidative stress. More significant, however, are observations that the cell's metabolic state can directly regulate transcription factor activity. For example, the DNA-binding activities of the CLOCK:BMAL1 and NPAS2:BMAL1 complexes have been reported as being directly regulated by the redox state of nicotinamide adenine dinucleotide (NAD and NADP) cofactors, in vitro (115). A criticism of these experiments, however, has been that as with many in vitro assays $(56,82)$, the concentrations of $\mathrm{NAD}(\mathrm{P})$ employed were probably supraphysiological and thus it remains to be firmly established whether or not this direct redox-regulation of "clock protein" activity is functionally relevant in vivo.

In a broader context there are several examples where circadian oscillations in the cellular concentrations of various universal metabolic intermediates have been shown, or can be reasonably inferred, to directly modulate the activity of enzymes that we know are responsible for circadian transcriptional rhythms. For example, gene expression at loci bound by many clock gene transcription factors is associated with chromatin remodeling via recruitment of assorted histone methyl- and acetyltransferases $(33,50,62,113)$. The activity of these enzymes is dependent upon the availability of their respective 1- and 2-carbon substrates (S-adenosylmethionine and acetyl-co-enzyme A [CoA], respectively). The availability of the activated forms of these enzymatic co-factors is dictated by rates of primary metabolism, for example, the ratio of acetyl-CoA to CoASH is largely determined by flux through the mitochondrial citric acid cycle and fatty acid oxidation. Since there is ample evidence that mitochondrial metabolism

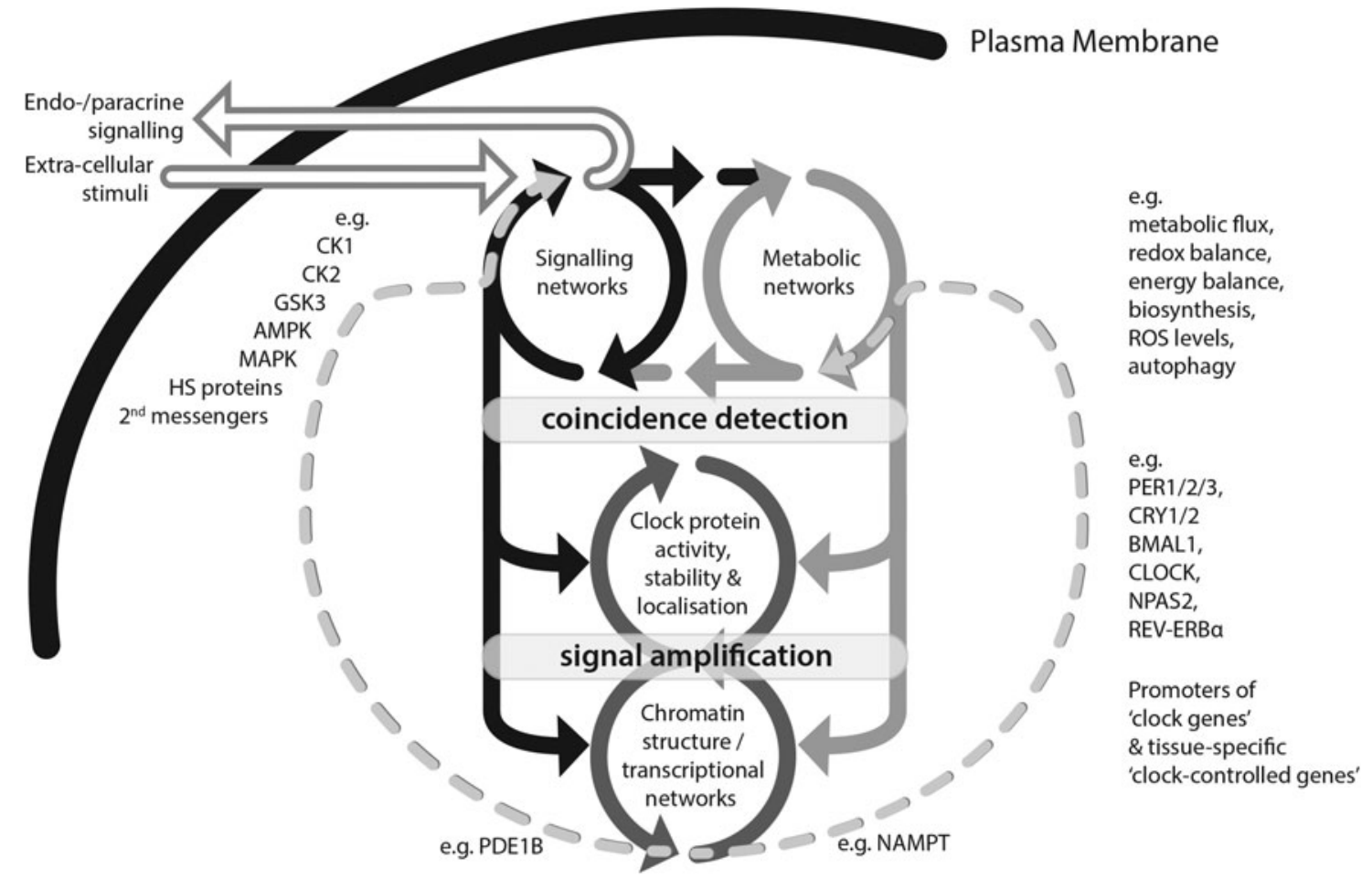

FIG. 4. A general model for mammalian cellular circadian timekeeping. Circadian timekeeping is functionally distributed within the cell's metabolic and signaling networks (top level) and persists in the absence of nascent gene expression, as in erythrocytes. In most (nucleated) cells however, the timing information sustained within this distributed network is communicated through phase-dependent regulation of protein activity, stability, and localization as observed, for example, in the canonical "clock protein" transcription factors (middle level). These act as coincidence-detecting substrate effectors that effectively "read" changes in the cytosolic network state over time, and "write" it into changes in nuclear chromatin structure and gene expression (lower level). Rhythmic modulation of chromatin structure by "clock proteins" facilitates co-ordinated temporal regulation of downstream gene expression circuits, including their own cognate clock gene promoters, resulting in signal amplification. Signal-to-noise is further increased by phase-specific protein and mRNA degradation, which imparts directionality to the circadian cycle. Rhythmic modulation of "clock-controlled genes" facilitates co-ordinated temporal regulation of physiology, and feeds forward into metabolic/signaling networks (dotted curved arrows), modulating expression of some component mechanisms, for example, rhythmic NAMPT expression facilitates rhythmic activity of the NAD ${ }^{+}$ salvage pathway (106), PDE1B degrades cAMP and affects rhythmic amplitude (143). The circadian state of the signaling network modulates communication with local and distant targets, while selectively and temporally gating the capacity of relevant extracellular signals to modulate circadian phase (solid horizontal arrows at top represent signaling over the plasma membrane). cAMP, cyclic AMP; NAMPT, nicotinamide phosphoribosyltransferase; PDE, phosphodiesterase. 
is circadian-regulated, it is quite likely that this will drive rhythms in activated co-factor availability and thereby feedback from primary metabolism to facilitate a more global modulation of chromatin remodeling enzyme activity within the nucleus $(30,89)$.

Second, the stability of PER2 and activity of BMAL1, are additionally regulated by dynamic lysine acetylation $(3,94)$ and are deacetylated via specific recruitment of deacetylase SIRT1, which also targets histone $\mathrm{H} 3$, in an $\mathrm{NAD}^{+}$-dependent manner. This deacetylation facilitates the transition from active to transcriptionally repressive/inactive clock protein complexes later in the circadian cycle, again in a manner dependent on primary metabolism, in this case $\mathrm{NAD}^{+}$availability-which is observed to be circadian $(59,106)$.

Finally, it is highly significant that several of the identified "clock gene" transcription factors are heme-binding proteins and exhibit reciprocal regulation between rhythmic heme metabolism and the heme protein's redox/ligand status, for example, heme binding and thus activity of the nuclear receptor REV-ERB $\beta$ is governed by a redox-sensitive cysteine $(43,55)$.

Of course more investigation is required into the specifics of redox and metabolic regulation of circadian gene expression: how does it vary between tissues, for example? Based on the examples above, however, it seems reasonable to expect an impending flood of observations detailing how metabolic cues can directly regulate the activity of circadian-relevant transcription factors and cellular rhythms in general. Moreover, since the stability and localization of identified clock proteins is regulated post-translationally, via phosphorylation/ubiquitination, through enzyme systems that appear to be conserved throughout the eukaryotes; it is not clear that the mRNA levels of the "clock gene" transcription factors actually need to oscillate for them to fulfill their role, merely that sufficient mRNA be present at the appropriate circadian phase to facilitate translation of nascent polypeptide chains (102). Clearly, however, as with cycles of transcriptional activation/repression, the degradation of these transcription factors and their mRNAs will increase the signal-to-noise ratio within this molecular circuit and thereby impart directionality to the cycle. This scenario is very much reminiscent of the eukaryotic cell cycle, which also features a highly conserved set of (cyclin-dependent) kinases, whereas their transcriptional targets vary widely between phyla (45).

The inference therefore is that the well-characterized autoregulatory circadian transcriptional-translational feedback circuitry in mammals may well be of secondary importance to timekeeping at the cellular level—although it surely facilitates greater amplitude of output and increased robustness-but is of prime importance for sustaining functional outputs at the level of physiology (see Fig. 4).

\section{Innovation}

This review highlights the many advances that have been made, and questions that remain, in our understanding of how the circadian clock works in mammals, and how it interacts with primary metabolism and redox regulation. Although rhythms of clock gene expression are essential for normal physiology, they do not seem sufficient to account for how individual cells keep time (100).

\section{Conclusions}

At the organismal level or in a whole tissue, rhythms in metabolism and redox balance can readily be viewed as an output from exquisitely co-ordinated circadian cycles of gene expression, in vivo. At the level of the cell, however, metabolism and redox balance appear to constitute both a rhythmic output from, and also a rhythmic input into the clock, and so become indistinguishable from a timekeeping component. Recent observations suggest that metabolic and redox rhythms persist in the absence of cycling clock gene expression. We are therefore of the view that when trying to understand the mechanism of cellular timekeeping, it is no longer helpful to consider any kind of transcriptional "core clock" mechanism that is somehow distinct from the milieu of metabolic, redox, signaling, and enzymatic oscillations within which the nuclear gene expression machinery lives. It seems more likely that "the cell... is the correct level of abstraction" at which to grapple with this problem (97).

\section{Future Questions}

1. Is circadian timekeeping an emergent property of the cell in mammals, or can it be reconstituted from a defined set of molecular components, as in cyanobacteria? For example, is the cell membrane required?

2. How does the gene expression apparatus distinguish circadian-relevant metabolic, redox, and signaling cues from irrelevant ones?

3. Are circadian rhythms of ROS production observable in every mammalian cell type, do they take place globally or are they restricted to sub-cellular organelles and/or microdomains?

4. What is the metabolic phenotype of cells from clock mutant mice, which lack cycling "clock gene" expression.

5. Are the steady-state levels of metabolic intermediates, such as acetyl-CoA, the primary means by which clockrelevant information is conveyed from metabolic processes to effect co-ordinated circadian changes in nuclear gene expression?

\section{Acknowledgments}

We would like to thank the Medical Research Council (MC_UP_1201/4) and the Wellcome Trust (093734/Z/10/Z) for funding our work. We are indebted to Mr P. Margiotta and Mr L. Hillier, LMB Visual Aids Department, for assistance with the figures.

\section{References}

1. Akhtar RA, Reddy AB, Maywood ES, Clayton JD, King VM, Smith AG, Gant TW, Hastings MH, and Kyriacou CP. Circadian cycling of the mouse liver transcriptome, as revealed by cDNA microarray, is driven by the suprachiasmatic nucleus. Curr Biol 12: 540-550, 2002.

2. Aon MA, Cortassa S, Marban E, and O'Rourke B. Synchronized whole cell oscillations in mitochondrial metabolism triggered by a local release of reactive oxygen species in cardiac myocytes. J Biol Chem 278: 44735-44744, 2003.

3. Asher G, Gatfield D, Stratmann M, Reinke H, Dibner C, Kreppel F, Mostoslavsky R, Alt FW, and Schibler U. SIRT1 regulates circadian clock gene expression through PER2 deacetylation. Cell 134: 317-328, 2008. 
4. Asher G and Schibler U. Crosstalk between components of circadian and metabolic cycles in mammals. Cell Metab 13: 125-137, 2011.

5. Atwood A, DeConde R, Wang SS, Mockler TC, Sabir JS, Ideker T, and Kay SA. Cell-autonomous circadian clock of hepatocytes drives rhythms in transcription and polyamine synthesis. Proc Natl Acad Sci U S A 108: 18560-18565, 2011.

6. Bae YS, Oh H, Rhee SG, and Yoo YD. Regulation of reactive oxygen species generation in cell signaling. Mol Cells 32: 491-509, 2011.

7. Balsalobre A, Brown SA, Marcacci L, Tronche F, Kellendonk C, Reichardt HM, Schutz G, and Schibler U. Resetting of circadian time in peripheral tissues by glucocorticoid signaling. Science 289: 2344-2347, 2000.

8. Bass J. Physiology: on time metabolism. Nature 480: 466467, 2011.

9. Bass J. Circadian topology of metabolism. Nature 491: 348356, 2012.

10. Blanco RA, Ziegler TR, Carlson BA, Cheng PY, Park Y, Cotsonis GA, Accardi CJ, and Jones DP. Diurnal variation in glutathione and cysteine redox states in human plasma. Am J Clin Nutr 86: 1016-1023, 2007.

11. Brown TM and Piggins HD. Electrophysiology of the suprachiasmatic circadian clock. Prog Neurobiol 82: 229-255, 2007.

12. Bunger MK, Wilsbacher LD, Moran SM, Clendenin C, Radcliffe LA, Hogenesch JB, Simon MC, Takahashi JS, and Bradfield CA. Mop3 is an essential component of the master circadian pacemaker in mammals. Cell 103: 10091017, 2000.

13. Chakravarthi $S$ and Bulleid NJ. Glutathione is required to regulate the formation of native disulfide bonds within proteins entering the secretory pathway. J Biol Chem 279: 39872-39879, 2004.

14. Chandel NS, McClintock DS, Feliciano CE, Wood TM, Melendez JA, Rodriguez AM, and Schumacker PT. Reactive oxygen species generated at mitochondrial complex III stabilize hypoxia-inducible factor-1alpha during hypoxia: a mechanism of O2 sensing. J Biol Chem 275: 2513025138, 2000.

15. Chen Z, Odstrcil EA, Tu BP, and McKnight SL. Restriction of DNA replication to the reductive phase of the metabolic cycle protects genome integrity. Science 316: 1916-1919, 2007.

16. Cho H, Zhao X, Hatori M, Yu RT, Barish GD, Lam MT, Chong LW, DiTacchio L, Atkins AR, Glass CK, Liddle C, Auwerx J, Downes M, Panda S, and Evans RM. Regulation of circadian behaviour and metabolism by REV-ERB-alpha and REV-ERB-beta. Nature 485: 123-127, 2012.

17. Colwell CS. Linking neural activity and molecular oscillations in the SCN. Nat Rev Neurosci 12: 553-569, 2011.

18. Cretenet G, Le Clech M, and Gachon F. Circadian clockcoordinated $12 \mathrm{Hr}$ period rhythmic activation of the IRE1alpha pathway controls lipid metabolism in mouse liver. Cell Metab 11: 47-57, 2010.

19. Dalle-Donne I, Rossi R, Colombo G, Giustarini D, and Milzani A. Protein S-glutathionylation: a regulatory device from bacteria to humans. Trends Biochem Sci 34: 85-96, 2009.

20. Dallmann R, Viola AU, Tarokh L, Cajochen C, and Brown SA. The human circadian metabolome. Proc Natl Acad Sci U S A 109: 2625-2629, 2012.

21. Damiola F, Le Minh N, Preitner N, Kornmann B, FleuryOlela F, and Schibler U. Restricted feeding uncouples cir- cadian oscillators in peripheral tissues from the central pacemaker in the suprachiasmatic nucleus. Genes Dev 14: 2950-2961, 2000.

22. Dansen TB, Smits LM, van Triest MH, de Keizer PL, van Leenen D, Koerkamp MG, Szypowska A, Meppelink A, Brenkman AB, Yodoi J, Holstege FC, and Burgering BM. Redox-sensitive cysteines bridge p300/CBP-mediated acetylation and FoxO4 activity. Nat Chem Biol 5: 664-672, 2009.

23. Davidson AJ. Lesion studies targeting food-anticipatory activity. Eur J Neurosci 30: 1658-1664, 2009.

24. Deery MJ, Maywood ES, Chesham JE, Sladek M, Karp NA, Green EW, Charles PD, Reddy AB, Kyriacou CP, Lilley KS, and Hastings $\mathrm{MH}$. Proteomic analysis reveals the role of synaptic vesicle cycling in sustaining the suprachiasmatic circadian clock. Curr Biol 19: 2031-2036, 2009.

25. Dibner C, Sage D, Unser M, Bauer C, d'Eysmond T, Naef F, and Schibler U. Circadian gene expression is resilient to large fluctuations in overall transcription rates. $E M B O J 28$ : 123-134, 2009.

26. Dickinson BC and Chang CJ. Chemistry and biology of reactive oxygen species in signaling or stress responses. Nat Chem Biol 7: 504-511, 2011.

27. Doherty CJ and Kay SA. Circadian control of global gene expression patterns. Annu Rev Genet 44: 419-444, 2010.

28. Duffield GE. DNA microarray analyses of circadian timing: the genomic basis of biological time. J Neuroendocrinol 15: 991-1002, 2003.

29. Dunlap JC. Molecular bases for circadian clocks. Cell 96: 271-290, 1999.

30. Eckel-Mahan KL, Patel VR, Mohney RP, Vignola KS, Baldi $\mathrm{P}$, and Sassone-Corsi P. Coordination of the transcriptome and metabolome by the circadian clock. Proc Natl Acad Sci U S A 109: 5541-5546, 2012.

31. Edgar RS, Green EW, Zhao Y, van Ooijen G, Olmedo M, Qin X, Xu Y, Pan M, Valekunja UK, Feeney KA, Maywood ES, Hastings MH, Baliga NS, Merrow M, Millar AJ, Johnson $\mathrm{CH}$, Kyriacou CP, O'Neill JS, and Reddy AB. Peroxiredoxins are conserved markers of circadian rhythms. Nature 485: 459-464, 2012.

32. Elimam A and Marcus C. Meal timing, fasting and glucocorticoids interplay in serum leptin concentrations and diurnal profile. Eur J Endocrinol 147: 181-188, 2002.

33. Etchegaray JP, Lee C, Wade PA, and Reppert SM. Rhythmic histone acetylation underlies transcription in the mammalian circadian clock. Nature 421: 177-182, 2003.

34. Finkel $\mathrm{T}$ and Holbrook NJ. Oxidants, oxidative stress and the biology of ageing. Nature 408: 239-247, 2000.

35. Forman HJ, Maiorino M, and Ursini F. Signaling functions of reactive oxygen species. Biochemistry 49: 835-842, 2010.

36. Froy O. Cytochrome P450 and the biological clock in mammals. Curr Drug Metab 10: 104-115, 2009.

37. Fustin JM, Doi M, Yamada H, Komatsu R, Shimba S, and Okamura H. Rhythmic nucleotide synthesis in the liver: temporal segregation of metabolites. Cell Rep 1: 341-349, 2012.

38. Garcia-Garcia A, Rodriguez-Rocha H, Madayiputhiya N, Pappa A, Panayiotidis MI, and Franco R. Biomarkers of protein oxidation in human disease. Curr Mol Med 12: 681697, 2012.

39. Gerber A, Esnault C, Aubert G, Treisman R, Pralong F, and Schibler U. Blood-borne circadian signal stimulates daily oscillations in actin dynamics and SRF activity. Cell 152: 492-503, 2013. 
40. Gibbs JE, Blaikley J, Beesley S, Matthews L, Simpson KD, Boyce SH, Farrow SN, Else KJ, Singh D, Ray DW, and Loudon AS. The nuclear receptor REV-ERBalpha mediates circadian regulation of innate immunity through selective regulation of inflammatory cytokines. Proc Natl Acad Sci U S A 109: 582-587, 2012.

41. Griffon N, Baudin V, Dieryck W, Dumoulin A, Pagnier J, Poyart C, and Marden MC. Tetramer-dimer equilibrium of oxyhemoglobin mutants determined from auto-oxidation rates. Protein Sci 7: 673-680, 1998.

42. Gruning NM, Lehrach H, and Ralser M. Regulatory crosstalk of the metabolic network. Trends Biochem Sci35: 220-227, 2010.

43. Gupta N and Ragsdale SW. Thiol-disulfide redox dependence of heme binding and heme ligand switching in nuclear hormone receptor rev-erb\{beta\}. J Biol Chem 286: 43924403, 2011.

44. Hall A, Karplus PA, and Poole LB. Typical 2-Cys peroxiredoxins-structures, mechanisms and functions. FEBS J 276: 2469-2477, 2009.

45. Hastings MH, Maywood ES, and O'Neill JS. Cellular circadian pacemaking and the role of cytosolic rhythms. Curr Biol 18: R805-R815, 2008.

46. Herzog ED, Aton SJ, Numano R, Sakaki Y, and Tei H. Temporal precision in the mammalian circadian system: a reliable clock from less reliable neurons. J Biol Rhythms 19: 35-46, 2004.

47. Hewitt JA, Kilmartin JV, Eyck LF, and Perutz MF. Noncooperativity of the dimer in the reaction of hemoglobin with oxygen (human-dissociation-equilibrium-sulfhydrylabsorption-x-ray analysis). Proc Natl Acad Sci U S A 69: 203207, 1972.

48. Hirota T, Okano T, Kokame K, Shirotani-Ikejima H, Miyata T, and Fukada Y. Glucose down-regulates Per1 and Per2 mRNA levels and induces circadian gene expression in cultured Rat-1 fibroblasts. J Biol Chem 277: 44244-44251, 2002.

49. Hogenesch JB and Ueda HR. Understanding systems-level properties: timely stories from the study of clocks. Nat Rev Genet 12: 407-416, 2011.

50. Hosoda H, Kato K, Asano H, Ito M, Kato H, Iwamoto T, Suzuki A, Masushige S, and Kida S. CBP/p300 is a cell type-specific modulator of CLOCK/BMAL1-mediated transcription. Mol Brain 2: 34, 2009.

51. Isojima $Y$, Nakajima $M$, Ukai $H$, Fujishima $H$, Yamada RG, Masumoto KH, Kiuchi R, Ishida M, Ukai-Tadenuma M, Minami Y, Kito R, Nakao K, Kishimoto W, Yoo SH, Shimomura K, Takao T, Takano A, Kojima T, Nagai K, Sakaki Y, Takahashi JS, and Ueda HR. CKIepsilon/deltadependent phosphorylation is a temperature-insensitive, period-determining process in the mammalian circadian clock. Proc Natl Acad Sci U S A 106: 15744-15749, 2009.

52. Jessop CE and Bulleid NJ. Glutathione directly reduces an oxidoreductase in the endoplasmic reticulum of mammalian cells. J Biol Chem 279: 55341-55347, 2004.

53. Johnson $\mathrm{CH}$. Circadian clocks and cell division: what's the pacemaker? Cell Cycle 9: 3864-3873, 2010.

54. Jouffe C, Cretenet G, Symul L, Martin E, Atger F, Naef F, and Gachon F. The circadian clock coordinates ribosome biogenesis. PLoS Biol 11: e1001455, 2013.

55. Kaasik K and Lee CC. Reciprocal regulation of haem biosynthesis and the circadian clock in mammals. Nature 430: 467-471, 2004.

56. Kaeberlein M, McDonagh T, Heltweg B, Hixon J, Westman EA, Caldwell SD, Napper A, Curtis R, DiStefano PS, Fields
S, Bedalov A, and Kennedy BK. Substrate-specific activation of sirtuins by resveratrol. J Biol Chem 280: 17038-17045, 2005.

57. Kakihana T, Nagata K, and Sitia R. Peroxides and peroxidases in the endoplasmic reticulum: integrating redox homeostasis and oxidative folding. Antioxid Redox Signal 16: 763-771, 2012.

58. Kalsbeek A, van der Spek R, Lei J, Endert E, Buijs RM, and Fliers E. Circadian rhythms in the hypothalamo-pituitaryadrenal (HPA) axis. Mol Cell Endocrinol 349: 20-29, 2012.

59. Kaminsky YG, Kosenko EA, and Kondrashova MN. Analysis of the circadian rhythm in energy metabolism of rat liver. Int J Biochem 16: 629-639, 1984.

60. Karisch R, Fernandez M, Taylor P, Virtanen C, St-Germain JR, Jin LL, Harris IS, Mori J, Mak TW, Senis YA, Ostman A, Moran MF, and Neel BG. Global proteomic assessment of the classical protein-tyrosine phosphatome and "Redoxome". Cell 146: 826-840, 2011.

61. Kasukawa T, Sugimoto M, Hida A, Minami Y, Mori M, Honma S, Honma K, Mishima K, Soga T, and Ueda HR. Human blood metabolite timetable indicates internal body time. Proc Natl Acad Sci U S A 109: 15036-15041, 2012.

62. Katada S and Sassone-Corsi P. The histone methyltransferase MLL1 permits the oscillation of circadian gene expression. Nat Struct Mol Biol 17: 1414-1421, 2010.

63. Kell DB. Iron behaving badly: inappropriate iron chelation as a major contributor to the aetiology of vascular and other progressive inflammatory and degenerative diseases. BMC Med Genomics 2: 2, 2009.

64. Kil IS, Lee SK, Ryu KW, Woo HA, Hu MC, Bae SH, and Rhee SG. Feedback control of adrenal steroidogenesis via $\mathrm{H} 2 \mathrm{O} 2$-dependent, reversible inactivation of peroxiredoxin III in mitochondria. Mol Cell 46: 584-594, 2012.

65. Kim GH, Ryan JJ, and Archer SL. The role of redox signaling in epigenetics and cardiovascular disease. Antioxid Redox Signal 18: 1920-1936, 2013.

66. King VM, Chahad-Ehlers S, Shen S, Harmar AJ, Maywood ES, and Hastings MH. A hVIPR transgene as a novel tool for the analysis of circadian function in the mouse suprachiasmatic nucleus. Eur J Neurosci 17: 822-832, 2003.

67. Kinoshita A, Nakayama Y, Kitayama T, and Tomita M. Simulation study of methemoglobin reduction in erythrocytes. Differential contributions of two pathways to tolerance to oxidative stress. FEBS J 274: 1449-1458, 2007.

68. Koike N, Yoo SH, Huang HC, Kumar V, Lee C, Kim TK, and Takahashi JS. Transcriptional architecture and chromatin landscape of the core circadian clock in mammals. Science 338: 349-354, 2012.

69. Kojima S, Sher-Chen EL, and Green CB. Circadian control of mRNA polyadenylation dynamics regulates rhythmic protein expression. Genes Dev 26: 2724-2736, 2012.

70. Kondratov RV, Kondratova AA, Gorbacheva VY, Vykhovanets $\mathrm{OV}$, and Antoch MP. Early aging and age-related pathologies in mice deficient in BMAL1, the core componentof the circadian clock. Genes Dev 20: 1868-1873, 2006.

71. Kornmann B, Schaad O, Bujard H, Takahashi JS, and Schibler U. System-driven and oscillator-dependent circadian transcription in mice with a conditionally active liver clock. PLoS Biol 5: e34, 2007.

72. Kumaki Y, Ukai-Tadenuma M, Uno KD, Nishio J, Masumoto KH, Nagano M, Komori T, Shigeyoshi Y, Hogenesch JB, and Ueda HR. Analysis and synthesis of high-amplitude Cis-elements in the mammalian circadian clock. Proc Natl Acad Sci U S A 105: 14946-14951, 2008. 
73. Lakin-Thomas PL. Transcriptional feedback oscillators: maybe, maybe not. J Biol Rhythms 21: 83-92, 2006.

74. Lamia KA, Storch KF, and Weitz CJ. Physiological significance of a peripheral tissue circadian clock. Proc Natl Acad Sci U S A 105: 15172-15177, 2008.

75. Lamia KA, Sachdeva UM, DiTacchio L, Williams EC, Alvarez JG, Egan DF, Vasquez DS, Juguilon H, Panda S, Shaw RJ, Thompson CB, and Evans RM. AMPK regulates the circadian clock by cryptochrome phosphorylation and degradation. Science 326: 437-440, 2009.

76. Lamia KA, Papp SJ, Yu RT, Barish GD, Uhlenhaut NH, Jonker JW, Downes M, and Evans RM. Cryptochromes mediate rhythmic repression of the glucocorticoid receptor. Nature 480: 552-556, 2011.

77. Le Martelot G, Canella D, Symul L, Migliavacca E, Gilardi F, Liechti R, Martin O, Harshman K, Delorenzi M, Desvergne B, Herr W, Deplancke B, Schibler U, Rougemont J, Guex N, Hernandez N, Naef F, and Cycli XC. Genomewide RNA polymerase II profiles and RNA accumulation reveal kinetics of transcription and associated epigenetic changes during diurnal cycles. PLoS Biol 10: e1001442, 2012.

78. Leak RK, Card JP, and Moore RY. Suprachiasmatic pacemaker organization analyzed by viral transynaptic transport. Brain Res 819: 23-32, 1999.

79. Lee C, Etchegaray JP, Cagampang FR, Loudon AS, and Reppert SM. Posttranslational mechanisms regulate the mammalian circadian clock. Cell 107: 855-867, 2001.

80. Lee J, Moulik M, Fang Z, Saha P, Zou F, Xu Y, Nelson DL, Ma K, Moore DD, and Yechoor VK. Bmal1 and betacell clock are required for adaptation to circadian disruption and their loss of function leads to oxidative stress-induced beta-cell failure in mice. Mol Cell Biol 33: 2327-2338, 2013.

81. Leise TL, Wang CW, Gitis PJ, and Welsh DK. Persistent cell-autonomous circadian oscillations in fibroblasts revealed by six-week single-cell imaging of PER2::LUC bioluminescence. PLoS One 7: e33334, 2012.

82. Lin SJ, Ford E, Haigis M, Liszt G, and Guarente L. Calorie restriction extends yeast life span by lowering the level of NADH. Genes Dev 18: 12-16, 2004.

83. Lowrey PL, Shimomura K, Antoch MP, Yamazaki S, Zemenides PD, Ralph MR, Menaker M, and Takahashi JS. Positional syntenic cloning and functional characterization of the mammalian circadian mutation tau. Science 288: 483492, 2000.

84. Ma D, Panda S, and Lin JD. Temporal orchestration of circadian autophagy rhythm by C/EBPbeta. EMBO J 30: 4642-4651, 2011.

85. Maier B, Wendt S, Vanselow JT, Wallach T, Reischl S, Oehmke S, Schlosser A, and Kramer A. A large-scale functional RNAi screen reveals a role for CK2 in the mammalian circadian clock. Genes Dev 23: 708-718, 2009.

86. Marcheva B, Ramsey KM, Buhr ED, Kobayashi Y, Su H, Ko $\mathrm{CH}$, Ivanova G, Omura C, Mo S, Vitaterna MH, Lopez JP, Philipson LH, Bradfield CA, Crosby SD, JeBailey L, Wang X, Takahashi JS, and Bass J. Disruption of the clock components CLOCK and BMAL1 leads to hypoinsulinaemia and diabetes. Nature 466: 627-631, 2010.

87. Margittai E and Sitia R. Oxidative protein folding in the secretory pathway and redox signaling across compartments and cells. Traffic 12: 1-8, 2011.

88. Martin M, Macias M, Escames G, Leon J, and Acuna-Castroviejo D. Melatonin but not vitamins $C$ and $E$ maintains glutathione homeostasis in t-butyl hydroperoxide-induced mitochondrial oxidative stress. FASEB J 14: 1677-1679, 2000.

89. Masri S, Patel VR, Eckel-Mahan KL, Peleg S, Forne I, Ladurner AG, Baldi P, Imhof A, and Sassone-Corsi P. Circadian acetylome reveals regulation of mitochondrial metabolic pathways. Proc Natl Acad Sci U S A 110: 33393344, 2013.

90. Menet JS, Rodriguez J, Abruzzi KC, and Rosbash M. Nascent-Seq reveals novel features of mouse circadian transcriptional regulation. eLife 1: e00011, 2012.

91. Millar AJ, Short SR, Chua NH, and Kay SA. A novel circadian phenotype based on firefly luciferase expression in transgenic plants. Plant Cell 4: 1075-1087, 1992.

92. Minami Y, Kasukawa T, Kakazu Y, Iigo M, Sugimoto M, Ikeda S, Yasui A, van der Horst GT, Soga T, and Ueda HR. Measurement of internal body time by blood metabolomics. Proc Natl Acad Sci U S A 106: 9890-9895, 2009.

93. Mistlberger RE. Neurobiology of food anticipatory circadian rhythms. Physiol Behav 104: 535-545, 2011.

94. Nakahata Y, Kaluzova M, Grimaldi B, Sahar S, Hirayama J, Chen D, Guarente LP, and Sassone-Corsi P. The NAD+dependent deacetylase SIRT1 modulates CLOCK-mediated chromatin remodeling and circadian control. Cell 134: 329340, 2008.

95. Nakajima M, Imai K, Ito H, Nishiwaki T, Murayama $Y$, Iwasaki H, Oyama T, and Kondo T. Reconstitution of circadian oscillation of cyanobacterial KaiC phosphorylation in vitro. Science 308: 414-415, 2005.

96. Nathan C and Ding A. SnapShot: Reactive Oxygen Intermediates (ROI). Cell 140: 951-951; e952, 2010.

97. Noble D. Claude Bernard, the first systems biologist, and the future of physiology. Exp Physiol 93: 16-26, 2008.

98. O'Neill JS and Reddy AB. Circadian clocks in human red blood cells. Nature 469: 498-503, 2011.

99. O'Neill JS, van Ooijen G, Dixon LE, Troein C, Corellou F, Bouget FY, Reddy AB, and Millar AJ. Circadian rhythms persist without transcription in a eukaryote. Nature 469: 554-558, 2011.

100. O'Neill JS, Maywood ES, and Hastings MH. Cellular circadian pacemaking and the role of cytosolic rhythms. In: Handbook of Experimental Pharmacology: Circadian Clocks, edited by Kramer A and Merrow M, Berlin, Heidelberg: Springer, 2013, pp. 67-103.

101. Panda S, Antoch MP, Miller BH, Su AI, Schook AB, Straume M, Schultz PG, Kay SA, Takahashi JS, and Hogenesch JB. Coordinated transcription of key pathways in the mouse by the circadian clock. Cell 109: 307-320, 2002.

102. Paulose JK, Rucker EB, 3rd, and Cassone VM. Toward the beginning of time: circadian rhythms in metabolism precede rhythms in clock gene expression in mouse embryonic stem cells. PLoS One 7: e49555, 2012.

103. Qin X, Byrne M, Xu Y, Mori T, and Johnson CH. Coupling of a core post-translational pacemaker to a slave transcription/translation feedback loop in a circadian system. PLOS Biol 8: e1000394, 2010.

104. Ralph MR, Foster RG, Davis FC, and Menaker M. Transplanted suprachiasmatic nucleus determines circadian period. Science 247: 975-978, 1990.

105. Ralser M, Wamelink MM, Kowald A, Gerisch B, Heeren G, Struys EA, Klipp E, Jakobs C, Breitenbach M, Lehrach H, and Krobitsch S. Dynamic rerouting of the carbohydrate flux is key to counteracting oxidative stress. J Biol 6: 10, 2007.

106. Ramsey KM, Yoshino J, Brace CS, Abrassart D, Kobayashi Y, Marcheva B, Hong HK, Chong JL, Buhr ED, Lee C, 
Takahashi JS, Imai S, and Bass J. Circadian clock feedback cycle through NAMPT-mediated NAD + biosynthesis. Science 324: 651-654, 2009.

107. Ray PD, Huang BW, and Tsuji Y. Reactive oxygen species (ROS) homeostasis and redox regulation in cellular signaling. Cell Signal 24: 981-990, 2012.

108. Reddy AB, Karp NA, Maywood ES, Sage EA, Deery M, O'Neill JS, Wong GK, Chesham J, Odell M, Lilley $\mathrm{KS}$, Kyriacou CP, and Hastings MH. Circadian orchestration of the hepatic proteome. Curr Biol 16: 1107-1115, 2006.

109. Reddy $\mathrm{AB}$ and $\mathrm{O}$ 'Neill JS. Healthy clocks, healthy body, healthy mind. Trends Cell Biol 20: 36-44, 2010.

110. Reppert SM and Weaver DR. Coordination of circadian timing in mammals. Nature 418: 935-941, 2002.

111. Rhee SG, Jeong W, Chang TS, and Woo HA. Sulfiredoxin, the cysteine sulfinic acid reductase specific to 2-Cys peroxiredoxin: its discovery, mechanism of action, and biological significance. Kidney Int Suppl S3-S8, 2007.

112. Rhee SG and Woo HA. Multiple functions of peroxiredoxins: peroxidases, sensors and regulators of the intracellular messenger $\mathrm{H}(2) \mathrm{O}(2)$, and protein chaperones. Antioxid Redox Signal 15: 781-794, 2011.

113. Ripperger JA and Schibler U. Rhythmic CLOCK-BMAL1 binding to multiple E-box motifs drives circadian Dbp transcription and chromatin transitions. Nat Genet 38: 369374, 2006.

114. Roenneberg $\mathrm{T}$ and Merrow M. "What watch?...such much!" Complexity and evolution of circadian clocks. Cell Tissue Res 309: 3-9, 2002.

115. Rutter J, Reick M, Wu LC, and McKnight SL. Regulation of clock and NPAS2 DNA binding by the redox state of NAD cofactors. Science 293: 510-514, 2001.

116. Saini C, Morf J, Stratmann M, Gos P, and Schibler U. Simulated body temperature rhythms reveal the phaseshifting behavior and plasticity of mammalian circadian oscillators. Genes Dev 26: 567-580, 2012.

117. Salway JG. Metabolism at a Glance. Malden, MA; Oxford: Blackwell, 2004.

118. Sani M, Ghanem-Boughanmi N, Gadacha W, Sebai H, Boughattas NA, Reinberg A, and Ben-Attia M. Malondialdehyde content and circadian variations in brain, kidney, liver, and plasma of mice. Chronobiol Int 24: 671685, 2007.

119. Schmutz I, Wendt S, Schnell A, Kramer A, Mansuy IM, and Albrecht U. Protein phosphatase 1 (PP1) is a posttranslational regulator of the mammalian circadian clock. PLoS One 6: e21325, 2011.

120. Schoeller DA, Cella LK, Sinha MK, and Caro JF. Entrainment of the diurnal rhythm of plasma leptin to meal timing. J Clin Invest 100: 1882-1887, 1997.

121. Storch KF and Weitz CJ. Daily rhythms of food-anticipatory behavioral activity do not require the known circadian clock. Proc Natl Acad Sci U S A 106: 6808-6813, 2009.

122. Sweeney BM and Haxo FT. Persistence of a photosynthetic rhythm in enucleated acetabularia. Science 134: 1361-1363, 1961.

123. Sweeney BM, Tuffli CF, Jr., and Rubin RH. The circadian rhythm in photosynthesis in Acetabularia in the presence of actinomycin D, puromycin, and chloramphenicol. J Gen Physiol 50: 647-659, 1967.

124. Szallasi Z, Stelling J, and Periwal V. System Modeling in Cell Biology: From Concepts to Nuts and Bolts. Cambridge, MA: MIT Press, 2006.
125. Tahara Y, Kuroda H, Saito K, Nakajima Y, Kubo Y, Ohnishi N, Seo Y, Otsuka M, Fuse Y, Ohura Y, Komatsu T, Moriya Y, Okada S, Furutani N, Hirao A, Horikawa K, Kudo T, and Shibata S. In vivo monitoring of peripheral circadian clocks in the mouse. Curr Biol 22: 1029-1034, 2012.

126. Teng SW, Mukherji S, Moffitt JR, de Buyl S, and O'Shea EK. Robust circadian oscillations in growing cyanobacteria require transcriptional feedback. Science 340: 737740, 2013.

127. Tomita J, Nakajima M, Kondo $T$, and Iwasaki $H$. No transcription-translation feedback in circadian rhythm of KaiC phosphorylation. Science 307: 251-254, 2005.

128. Tsiftsoglou AS, Tsamadou AI, and Papadopoulou LC. Heme as key regulator of major mammalian cellular functions: molecular, cellular, and pharmacological aspects. Pharmacol Ther 111: 327-345, 2006.

129. Tu BP, Kudlicki A, Rowicka M, and McKnight SL. Logic of the yeast metabolic cycle: temporal compartmentalization of cellular processes. Science 310: 11521158, 2005.

130. Ukai $\mathrm{H}$ and Ueda HR. Systems biology of mammalian circadian clocks. Annu Rev Physiol 72: 579-603, 2010.

131. Valekunja UK, Edgar RS, Oklejewicz M, van der Horst GT, O'Neill JS, Tamanini F, Turner DJ, and Reddy AB. Histone methyltransferase MLL3 contributes to genome-scale circadian transcription. Proc Natl Acad Sci U S A 110: 15541559, 2013.

132. Vitaterna $M H$, Selby $C P$, Todo $T$, Niwa $H$, Thompson $C$, Fruechte EM, Hitomi K, Thresher RJ, Ishikawa T, Miyazaki J, Takahashi JS, and Sancar A. Differential regulation of mammalian period genes and circadian rhythmicity by cryptochromes 1 and 2. Proc Natl Acad Sci U S A 96: 1211412119, 1999.

133. Vollmers C, Gill S, DiTacchio L, Pulivarthy SR, Le HD, and Panda S. Time of feeding and the intrinsic circadian clock drive rhythms in hepatic gene expression. Proc Natl Acad Sci U S A 106: 21453-21458, 2009.

134. Wang TA, Yu YV, Govindaiah G, Ye X, Artinian L, Coleman TP, Sweedler JV, Cox CL, and Gillette MU. Circadian rhythm of redox state regulates excitability in suprachiasmatic nucleus neurons. Science 337: 839-842, 2012.

135. Welsh DK, Logothetis DE, Meister M, and Reppert SM. Individual neurons dissociated from rat suprachiasmatic nucleus express independently phased circadian firing rhythms. Neuron 14: 697-706, 1995.

136. Welsh DK, Yoo SH, Liu AC, Takahashi JS, and Kay SA. Bioluminescence imaging of individual fibroblasts reveals persistent, independently phased circadian rhythms of clock gene expression. Curr Biol 14: 2289-2295, 2004.

137. Welsh DK, Takahashi JS, and Kay SA. Suprachiasmatic nucleus: cell autonomy and network properties. Annu Rev Physiol 72: 551-577, 2010.

138. Whaley-Connell A, McCullough PA, and Sowers JR. The role of oxidative stress in the metabolic syndrome. Rev Cardiovasc Med 12: 21-29, 2011.

139. Yamaguchi S, Mitsui S, Miyake S, Yan L, Onishi H, Yagita K, Suzuki M, Shibata S, Kobayashi M, and Okamura H. The $5^{\prime}$ upstream region of mPer1 gene contains two promoters and is responsible for circadian oscillation. Curr Biol 10: 873-876, 2000.

140. Yamazaki S, Numano R, Abe M, Hida A, Takahashi R, Ueda M, Block GD, Sakaki Y, Menaker M, and Tei H. Resetting central and peripheral circadian oscillators in transgenic rats. Science 288: 682-685, 2000. 
141. Yoo SH, Yamazaki S, Lowrey PL, Shimomura $\mathrm{K}, \mathrm{Ko} \mathrm{CH}$, Buhr ED, Siepka SM, Hong HK, Oh WJ, Yoo OJ, Menaker $\mathrm{M}$, and Takahashi JS. PERIOD2::LUCIFERASE real-time reporting of circadian dynamics reveals persistent circadian oscillations in mouse peripheral tissues. Proc Natl Acad Sci U S A 101: 5339-5346, 2004.

142. Yu EA and Weaver DR. Disrupting the circadian clock: gene-specific effects on aging, cancer, and other phenotypes. Aging 3: 479-493, 2011.

143. Zhang EE, Liu AC, Hirota T, Miraglia LJ, Welch G, Pongsawakul PY, Liu X, Atwood A, Huss JW, 3rd, Janes J, Su AI, Hogenesch JB, and Kay SA. A genome-wide RNAi screen for modifiers of the circadian clock in human cells. Cell 139: 199-210, 2009.

144. Zhang EE, Liu Y, Dentin R, Pongsawakul PY, Liu AC, Hirota T, Nusinow DA, Sun X, Landais S, Kodama $Y$, Brenner DA, Montminy M, and Kay SA. Cryptochrome mediates circadian regulation of cAMP signaling and hepatic gluconeogenesis. Nat Med 16: 1152-1156, 2010.

145. Zheng X, Yang Z, Yue Z, Alvarez JD, and Sehgal A. FOXO and insulin signaling regulate sensitivity of the circadian clock to oxidative stress. Proc Natl Acad Sci U S A 104: 15899-15904, 2007.

146. Zwicker D, Lubensky DK, and ten Wolde PR. Robust circadian clocks from coupled protein-modification and transcription-translation cycles. Proc Natl Acad Sci U S A 107: 22540-22545, 2010.

Address correspondence to: Dr. John S. O'Neill MRC Laboratory of Molecular Biology Cambridge Biomedical Campus Francis Crick Ave. Cambridge CB2 $0 Q H$ United Kingdom

E-mail: oneillj@mrc-lmb.cam.ac.uk

Date of first submission to ARS Central, September 10, 2013; date of acceptance, September 25, 2013.

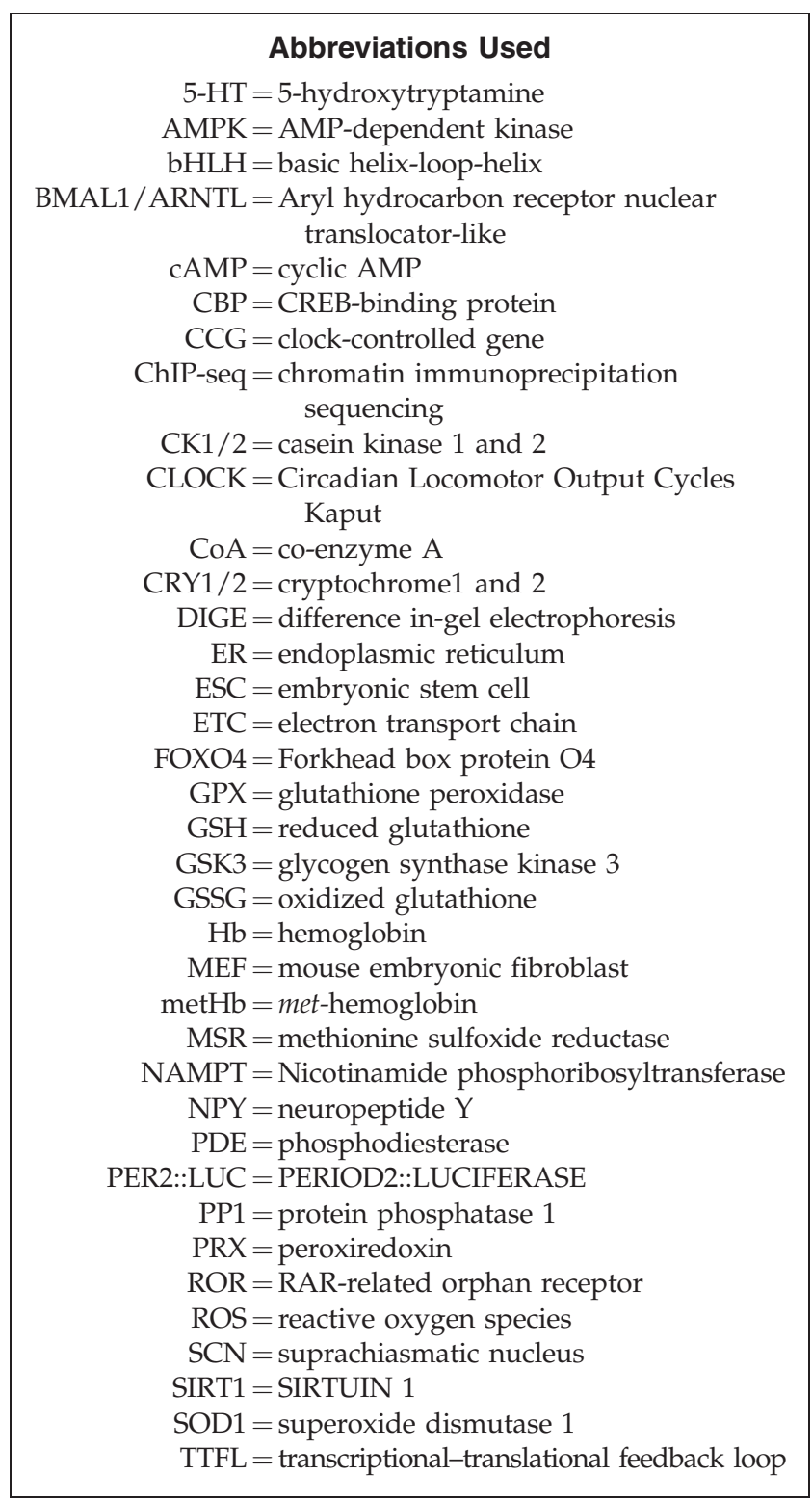

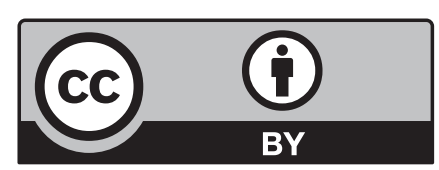

This work is licensed under a Creative Commons Attribution 3.0 United States License. You are free to copy, distribute, transmit and adapt this work, but you must attribute this work as "Antioxidants \& Redox Signaling. Copyright 2014 Mary Ann Liebert, Inc. http://liebertpub.com/ars, used under a Creative Commons Attribution License: http:// creativecommons.org/licenses/by/3.0/us/" 